\title{
Dynamic Fidelity Control to the Central Auditory System: Synergistic Glycine/GABAergic Inhibition in the Cochlear Nucleus
}

\author{
Jana Nerlich, ${ }^{1}$ Thomas Kuenzel, ${ }^{2}$ Christian Keine, ${ }^{1}$ Andrej Korenic, ${ }^{3}$ Rudolf Rübsamen, ${ }^{1}$ and Ivan Milenkovic ${ }^{4}$ \\ ${ }^{1}$ Faculty of Biosciences, Pharmacy and Psychology, University of Leipzig, 04103 Leipzig, Germany, ${ }^{2}$ Institute of Biology 2, RWTH Aachen University, 52062 \\ Aachen, Germany, ${ }^{3}$ Centre for Laser Microscopy, Department of Physiology and Biochemistry, Faculty of Biology, University of Belgrade, 11000 Belgrade, \\ Serbia, and ${ }^{4}$ Carl Ludwig Institute for Physiology, Faculty of Medicine, University of Leipzig, 04103 Leipzig, Germany
}

GABA and glycine are the major inhibitory transmitters that attune neuronal activity in the CNS of mammals. The respective transmitters are mostly spatially separated, that is, synaptic inhibition in the forebrain areas is mediated by GABA, whereas glycine is predominantly used in the brainstem. Accordingly, inhibition in auditory brainstem circuits is largely mediated by glycine, but there are few auditory synapses using both transmitters in maturity. Little is known about physiological advantages of such a two-transmitter inhibitory mechanism. We explored the benefit of engaging both glycine and GABA with inhibition at the endbulb of Held-spherical bushy cell synapse in the auditory brainstem of juvenile Mongolian gerbils. This model synapse enables selective in vivo activation of excitatory and inhibitory neuronal inputs through systemic sound stimulation and precise analysis of the input (endbulb of Held) output (spherical bushy cell) function. The combination of in vivo and slice electrophysiology revealed that the dynamic AP inhibition in spherical bushy cells closely matches the inhibitory conductance profile determined by the glycine- $\mathrm{R}$ and $\mathrm{GABA}_{\mathrm{A}}-\mathrm{R}$. The slow and potent glycinergic component dominates the inhibitory conductance, thereby primarily accounting for its high-pass filter properties. GABAergic transmission enhances the inhibitory strength and shapes its duration in an activity-dependent manner, thus increasing the inhibitory potency to suppress the excitation through the endbulb of Held. Finally, in silico modeling provides a strong link between in vivo and slice data by simulating the interactions between the endbulb- and the synergistic glycine-GABA-conductances during in vivo-like spontaneous and sound evoked activities.

Key words: AP inhibition; auditory signal processing; GABAA/glycine receptors; in vivo electrophysiology; modeling; slice electrophysiology

\section{Introduction}

Inhibitory synapses in the adult mammalian CNS provide a functional balance of neuronal activity through release of GABA or glycine. GABA mediates inhibition mainly in the cortex and cerebellum, whereas fast glycinergic transmission is predominantly restricted to the brainstem and spinal cord (Fritschy et al., 1994; Legendre, 2001; Huang et al., 2007; Lehmann et al., 2012). Similar patterns of respective neurotransmitters were also described for the central auditory system (Prieto et al., 1994; Kurt et al., 2006; Caspary et al., 2008; Friauf et al., 2011; Sanes and Kotak, 2011).

Received Feb. 19, 2014; revised July 16, 2014; accepted July 17, 2014.

Author contributions: J.N., T.K., R.R., and I.M. designed research; J.N., T.K., and C.K. performed research; J.N., T.K., C.K., A.K., and I.M. analyzed data; T.K., R.R., and I.M. wrote the paper.

This work was supported by the Deutsche Forschungsgemeinschaft Grant MI 954/2-1 to I.M., Grant MI 954/1-1 to I.M., Grant RU 390/19-1 to R.R. and J.N., Grant GRK 1097 to J.N. and C.K., and Grant KU 2529/2-1 to T.K., A.K. was supported by the DAAD project "Akademischer Neuaufbau Südosteuropa." We thank Stefan Oline for providing the slope analysis routine for slice recordings.

The authors declare no competing financial interests.

Correspondence should be addressed to Dr. Ivan Milenkovic, Carl Ludwig Institute for Physiology, Faculty of Medicine, University of Leipzig, Liebigstrasse 27, D-04103 Leipzig, Germany. E-mail: Ivan.Milenkovic@medizin.uni-leipzig.de.

DOI:10.1523/JNEUROSCI.0719-14.2014

Copyright $\odot 2014$ the authors $\quad 0270-6474 / 14 / 3411604-17 \$ 15.00 / 0$
However, despite this general spatial differentiation, a number of special central synapses engage glycine and GABA signaling in terms of synaptic vesicle content, corelease, and activation of postsynaptic receptors (Triller et al., 1987; Burger et al., 1991; Bohlhalter et al., 1994; Todd et al., 1996; Dumba et al., 1998; Jonas et al., 1998). In the auditory system, GABA is associated with development when it evokes a transient membrane depolarization and ensuing calcium signaling (Sanes and Friauf, 2000; Kullmann and Kandler, 2001; Kullmann et al., 2002; Milenkovic et al., 2007; Witte et al., 2014). Inhibitory terminals in the lateral superior olive change the transmitter phenotype from GABA to glycine after hearing onset (Kotak et al., 1998; Nabekura et al., 2004; Kim and Kandler, 2010). Yet, persistent corelease of both transmitters was demonstrated at some brainstem synapses (Awatramani et al., 2005; Apostolides and Trussell, 2013). Spherical bushy cells (SBCs) in the anteroventral cochlear nucleus (AVCN) receive two types of acoustically triggered inputs: Excitation through the endbulbs of Held, and inhibitory inputs from AVCN D-stellate cells (Smith and Rhode, 1989; Campagnola and Manis, 2014) and dorsal cochlear nucleus tuberculoventral cells (Wickesberg and Oertel, 1990; Saint Marie et al., 1991). Slice experiments revealed a conspicuous inhibitory role of glycinergic 
signaling in SBCs (Harty and Manis, 1996; Lim et al., 1999, 2000; Xie and Manis, 2013), whereas in vivo recordings demonstrated a contribution of both glycine and GABA to attunement of firing properties (Caspary et al., 1994; Gai and Carney, 2008; Dehmel et al., 2010). Although synaptic inputs to SBCs have been extensively characterized in slice preparations from mice and rats, the function of $G A B A_{A}-R$ remained elusive (but for $G A B A_{B}-R$, see Lim et al., 2000; Chanda and Xu-Friedman, 2010). Moreover, a wealth of in vivo studies have been conducted in the AVCN of Mongolian gerbils, but matching characterization of inhibitory conductances is still lacking.

Here, we explored the interaction of glycine-and GABAergic inhibition at the endbulb of Held synapse using selective activation of inhibitory neuronal inputs through systemic sound stimulation. By performing juxtacellular recordings in vivo and whole-cell measurements in acute slices, we identified the mechanisms of SBC's coinhibition in juvenile Mongolian gerbils. The efficacy of glycine-GABA transmission was assessed over a range of physiologically relevant conductance interactions by implementing an in silico model. Our results provide evidence for synergistic GABA enhancement of predominantly glycinergic inhibition. The slow kinetics of glycine-GABA inhibitory currents shows a frequency-dependent buildup, thereby providing efficient dynamic control of AP firing.

\section{Materials and Methods}

The experimental procedures were approved by the Saxonian district Government Leipzig (T 93/11, T 84/12, T 67/13 and TVV 06/09) and conducted according to the European Communities Council Directive (86/609/EEC).

In vivo experiments. Recordings were performed in 9 Mongolian gerbils (Meriones unguiculatus) of either sex aged postnatal days 25-33 (P25-P33). Data were acquired on juvenile animals to circumvent the prolonged postnatal development of inhibitory transmission in auditory brainstem nuclei (Awatramani et al., 2005; Luján et al., 2008; Friauf et al., 2011; Milenkovic and Rübsamen, 2011). Recordings were performed in a sound-attenuated chamber (Type 400, Industrial Acoustic) while the animal was stabilized in a custom-made stereotaxic apparatus positioned on a vibration-isolated table.

Surgical preparation. Animals were anesthetized with an initial intraperitoneal injection of a mixture of ketamine hydrochloride $(0.18 \mathrm{mg} / \mathrm{g}$ body weight; Ketamin, Ratiopharm) and xylazine hydrochloride (7 $\mu \mathrm{g} / \mathrm{g}$ body weight; Rompun, Bayer). Anesthesia was maintained by additional subcutaneous application of one-third of the initial dose, approximately every 60-90 min during recording sessions. Gerbils were fixed in the stereotaxic device by a metal bolt glued to the skull exposed around the bregma point. The recording electrode was inserted through a hole (diameter $0.5 \mathrm{~mm}$ ) drilled $1.8-2 \mathrm{~mm}$ lateral to the midline and $2 \mathrm{~mm}$ caudal to the lambdoid suture. The reference electrode was placed in the superficial cerebellum through a second hole (diameter $0.5 \mathrm{~mm}$ ) located on the midline. The AVCN was approached dorsally by tilting the animal at $12^{\circ}-18^{\circ}$ to the midsagittal plane. Body temperature was kept between $36.5^{\circ} \mathrm{C}$ and $37.5^{\circ} \mathrm{C}$ with a temperature-controlled heating pad.

Acoustic stimulation. Auditory stimuli were digitally generated using custom-written MATLAB software (MathWorks). The stimuli were transferred to a D/A converter (RP2.1 real-time processor, $97.7 \mathrm{kHz}$ sampling rate, 24 bit, Tucker-Davis Technologies) and delivered through a custom-made earphone (acoustic transducer: DT 770 pro, Beyer Dynamics) fitted with a plastic tube (length $35 \mathrm{~mm}$, diameter $5 \mathrm{~mm}$ ) positioned into the outer ear canal at a distance of $\sim 4 \mathrm{~mm}$ to the eardrum.

The unit's frequency response area was obtained by a pseudorandom presentation of pure tone pulses (100 ms duration, $5 \mathrm{~ms}$ rise-fall time, $200 \mathrm{~ms}$ interstimulus interval) derived from a matrix of predefined frequency/intensity pairs ( 20 frequencies on a log scale, 10 intensity levels on linear scale, 3-5 repetitions). Based on the unit's frequency response area, its characteristic frequency $(\mathrm{CF}$, frequency to which neuron is most sensitive), the excitatory and inhibitory response threshold and the area of the high-frequency inhibitory sideband were assessed. For in-depth analyses, neuronal discharge activities were also recorded during repetitive stimulation (200-300 times) of single pure tones (1) at the unit's CF and (2) within the inhibitory sideband (100 ms duration, $5 \mathrm{~ms}$ rise-fall time, $300 \mathrm{~ms}$ interstimulus interval). Sound pressure level was set $20 \mathrm{~dB}$ above the respective thresholds.

Single-unit recording. Considering the tonotopic organization of the AVCN (Kopp-Scheinpflug et al., 2002; Dehmel et al., 2010), the multiunit activity at the rostral pole was initially assessed with low impedance glass micropipettes (GB150F-10, Science Products, 1-5 $\mathrm{M} \Omega$ filled with $3 \mathrm{M} \mathrm{KCl}$ ) to narrow down the target area (frequencies $<5 \mathrm{kHz}$ ). Then, juxtacellular single-unit recordings (electrodes 7-10 $\mathrm{m} \Omega$ ) were performed on spherical bushy cells, which were identified according to the characteristic waveform (Pfeiffer, 1966; Winter and Palmer, 1990; Englitz et al., 2009; Typlt et al., 2010), and the primary-like peristimulus time histogram pattern (Blackburn and Sachs, 1989).

Recorded voltage signals were amplified (Neuroprobe 1600, A-M Systems), and digitized at a sampling rate of $97.7 \mathrm{kHz}$ (24 bit, RP2.1, TuckerDavis Technologies). Signals were bandpass filtered between $50 \mathrm{~Hz}$ and 5 $\mathrm{kHz}$ using a zero-phase forward and reverse digital IIR filter and stored for offline analysis using custom-written MATLAB software (version 8.1, MathWorks). Recordings were selected for further analysis according to three criteria: (1) SD (AP height)/mean (AP height) $<20 \%(10.4 \pm 3.9 \%$, $n=16$ ), (2) uniform waveforms, and (3) signal-to-noise ratio $>12$ $(16.1 \pm 5.1, n=16)$.

Spontaneous and stimulus evoked AP firing in SBCs is characterized by the typical voltage signature composed of two or three components (P-A-B; see Fig. 1A), indicating the discharge of the presynaptic endbulb (P), the postsynaptic EPSP (A), and the postsynaptic AP (B) (Englitz et al., 2009; Typlt et al., 2010). The components were distinguished by means of hierarchical clustering after dimension reduction using principal component analysis. For the waveforms containing all three components, the inflection point at the rising flank of the voltage signal was determined as the EPSP position by calculating the local minimum of the first derivative preceding the AP peak. For signals with an EPSP separated from the AP, the first local maximum preceding the AP was considered the EPSP peak. Time between the EPSP and the peak of the AP indicated the EPSP-to-AP transition time. Average rising slope of the EPSP was calculated between $20 \%$ and $80 \%$ of the EPSP amplitude.

For histological verification of recording site, Fluorogold was iontophoretically injected at the end of recording session ( $4 \mu \mathrm{A}$ for $7 \mathrm{~min})$. The animal was perfused $4-6 \mathrm{~h}$ thereafter with $0.9 \% \mathrm{NaCl}$ solution followed by $5 \%$ PFA. After overnight postfixation, the brain was cut on a vibratome (Microm HM 650) and the tissue sections (100 $\mu \mathrm{m}$ thick) were visualized under the confocal laser scanning microscope (TCS PS5, Leica).

Slice preparation. Coronal slices $(170 \mu \mathrm{m})$ containing rostral AVCN were cut from P22-P33 gerbils of either sex (Milenkovic et al., 2007; Dietz et al., 2012). The rationale was to perform the experiments on a rather developed system matching the acquired in vivo data. The brainstem was sliced with a vibratome, in low-calcium ACSF solution containing the following (in mM): $125 \mathrm{NaCl}, 2.5 \mathrm{KCl}, 0.1 \mathrm{CaCl}_{2}, 3 \mathrm{MgCl}_{2}, 1.25$ $\mathrm{NaH}_{2} \mathrm{PO}_{4}, 25 \mathrm{NaHCO}_{3}, 25$ glucose, 2 sodium pyruvate, 3 myoinositol, 0.5 ascorbic acid, continuously bubbled with $5 \% \mathrm{CO}_{2}$ and $95 \% \mathrm{O}_{2}, \mathrm{pH}$ 7.4. Slices were incubated in the standard recording solution (ACSF same as for slicing, except $\mathrm{CaCl}_{2}$ and $\mathrm{MgCl}_{2}$ were changed to 2 and $1 \mathrm{~mm}$, respectively) for $30 \mathrm{~min}$ at $37^{\circ} \mathrm{C}$ and stored at room temperature until recording. Experiments were made at nearly physiological temperature $\left(33 \pm 0.5^{\circ} \mathrm{C}\right)$.

Perforated-patch and whole-cell recordings. Gramicidin perforatedpatch recordings on large SBCs were acquired as previously described (Witte et al., 2014). Patch pipettes were pulled with Narishige PC-10 vertical puller from filamented borosilicate glass capillaries (Science Products) to have resistances of 5-6 $\mathrm{M} \Omega$ when filled with a $\mathrm{K}^{+}$. gluconate-based internal solution. The potassium-based solution was used to avoid the potential effect of $\mathrm{Cs}^{+}$ions on the transport activity of KCC2 (Kakazu et al., 1999). Pipettes were tip-filled as follows (mM): 97.5 potassium-gluconate, $32.5 \mathrm{KCl}, 1 \mathrm{MgCl}_{2}, 10 \mathrm{HEPES}, 5$ EGTA, $10 \mathrm{HEPES}$, 
pH 7.34 with $\mathrm{KOH}$ (290 mOsm adjusted with sucrose). The remainder of the pipette was back-filled with the same solution including gramicidin (30 $\mu \mathrm{g} / \mathrm{ml}$ gramicidin A, Sigma) and $25 \mu \mathrm{M}$ ATTO 488. The latter was used to confirm that the perforated patch was not ruptured. After the experiment, the rupture of the perforated-patch yielded depolarizing IPSPs (due to $34.5 \mathrm{mM} \mathrm{Cl}^{-}$), thus confirming that the gramicidin ionophores were impermeable for $\mathrm{Cl}^{-}$and that recordings were not affected by the $\left[\mathrm{Cl}_{\text {pip }}^{-}\right]$. The progress of perforation was evaluated by monitoring the steady-state current responses to a $-5 \mathrm{mV}$ voltage command. The series resistance typically reached a steady level (mean Rs $=18.3 \pm 0.7$ $\mathrm{M} \Omega$, bridge $=21.9 \pm 0.7 \mathrm{M} \Omega, n=5$ ) within $30-40 \mathrm{~min}$ after the giga-seal formation and the experiments were started thereafter.

The recordings of synaptically evoked IPSCs (eIPSCs) on SBCs were conducted as described previously (Dietz et al., 2012). The pipettes had resistances of $4-5 \mathrm{M} \Omega$ when filled with (mM) as follows: $140 \mathrm{CsMeSO}_{3}, 20$ TEA-Cl, $3.3 \mathrm{MgCl}_{2}$, 10 HEPES, 0.1 EGTA, 5 QX-314-Cl, 5 phosphocreatine, 2 ATP disodium salt, 0.3 GTP disodium salt, and $0.2 \%$ biocytin ( $\mathrm{pH} 7.3$ with $\mathrm{CsOH})$. For current-clamp recordings of eIPSPs the pipette solution contained the following $(\mathrm{mm}): 127$ potassium-gluconate, $3 \mathrm{KCl}$, $1 \mathrm{MgCl}_{2}, 10$ HEPES, 0.2 EGTA, 5 phosphocreatine, 2 ATP disodium salt, 0.3 GTP disodium salt, $\mathrm{pH}$ adjusted to 7.3 with $\mathrm{KOH}$. IPSCs and IPSPs were evoked by electrical stimulation of afferent fibers through a bipolar theta glass electrode (Sutter instruments, tip $\varnothing 5 \mu \mathrm{m}$ ) filled with bath solution and placed 30-60 $\mu \mathrm{m}$ adjacent to the cell. The stimulus intensity was slowly increased until set at the lowest value that reliably evoked IPSCs of stable amplitudes within a train. Pulse stimuli (100 $\mu$ s) were generated by a stimulator (Master 8) and delivered via an isolated stimulus unit (AMPI Iso-flex) to evoke either single events or train-responses at different frequencies. Current-clamp responses were recorded at -62 to $-66 \mathrm{mV}$, approximately corresponding to the resting membrane potential of bushy cells (McGinley and Oertel, 2006; Price and Trussell, 2006; Milenkovic et al., 2007), whereas voltage-clamp measurements were done from $V_{\text {hold }}=-71 \mathrm{mV}$. Pharmacological inhibition of glutamate $\left(50 \mu \mathrm{M} \mathrm{AP}-5,10 \mu \mathrm{M}\right.$ NBQX) and $\mathrm{GABA}_{\mathrm{B}}$ receptors ( $3 \mu \mathrm{M}$ CGP55845) was performed in all experiments. Offline correction of voltages was done for junction potentials of $11 \mathrm{mV}$ (VC) and $14 \mathrm{mV}$ (CC).

Glycine and GABA $(500 \mu \mathrm{M})$ were prepared in $\mathrm{HCO}_{3}{ }^{-}$-containing bath solution and pressure applied over the soma of recorded neuron using a Picospritzer (General Valve). As in all other experiments, extracellular solution was supplemented with the $\mathrm{GABA}_{\mathrm{B}}$ antagonist CGP 55845 . The constant stimulation conditions were assured by controlling the pipette diameter, application pressure and duration, and distance from the cell ( $3 \mu \mathrm{m}, 5 \mathrm{psi}, 5 \mathrm{~ms}, 10 \mu \mathrm{m}$, respectively). The perfusion was turned off just before each puff application to avoid unequal dilution of the agonist. Significance of the responses was determined by using the $z$ test, i.e., level of acceptance was set at $z>3.3\left(\mathrm{~V}_{\mathrm{m}}\right)$ or $z<-3.3\left(\mathrm{I}_{\mathrm{m}}\right)$, which corresponds to $p<0.001\left[z=(\mathrm{A}-\mathrm{BL}) / \mathrm{SD}_{\mathrm{BL}}\right.$, with A being the maximal amplitude of the response, BL the mean of the baseline $(2 \mathrm{~s}$ before stimulation), and $\mathrm{SD}_{\mathrm{BL}}$ the $\mathrm{SD}$ of the baseline]. Pressure ejection of ACSF under the same condition evoked no response (mean ACSF response $=-0.34 \pm 0.2 \mathrm{pA}, z=-0.21 \pm 0.13, p>0.73, n=4$ ), whereas glycine and GABA evoked significant membrane currents in the same neurons.

The recordings were acquired using a Multiclamp 700B amplifier (Molecular Devices). In voltage-clamp recordings, series resistance was compensated by $50 \%$ to remaining Rs of $4-7 \mathrm{~m} \Omega$. Bridge balance and pipette capacitance neutralization were adjusted throughout the experiment in current-clamp recordings. Recorded signals were digitized at $20 / 50 \mathrm{kHz}$ and filtered with a $6 \mathrm{kHz}$ Bessel low-pass filter. Data were examined with pClamp 10 software (Molecular Devices) followed by the analysis with custom-written MATLAB routines.

Data analysis. Mean peak amplitudes, $10-90 \%$ rise times, and decay time constants were analyzed from averaged traces ( $>7$ repetitions) with custom-written MATLAB routines. IPSC decay phase was fitted with biexponential function (between $95 \%$ and $5 \%$ of the peak amplitude). The weighted $\tau$ decay for biexponential fitting was calculated as follows: $\tau=\left(\mathrm{A}_{\text {fast }} \times \tau_{\text {fast }}+\mathrm{A}_{\text {slow }} \times \tau_{\text {slow }}\right) /\left(\mathrm{A}_{\text {fast }}+\mathrm{A}_{\text {slow }}\right)$, where $\mathrm{A}_{\text {fast }}$ and $\mathrm{A}_{\text {slow }}$ are amplitudes at $t=0$ and $\tau_{\text {fast }}$ and $\tau_{\text {slow }}$ are the fast and slow time constants, respectively. Calculation of IPSC conductance was based on

\section{Table 1. Biophysical parameters of the spherical bushy cell model ${ }^{a}$}

\begin{tabular}{ll}
\hline Parameters & \\
\hline Basic membrane properties & \\
$C_{m}$ & $20.1 \mathrm{pF}$ \\
$\mathrm{R}_{\mathrm{m}}$ & $69.2 \mathrm{M} \Omega$ \\
$\mathrm{V}_{\text {rest }}$ & $-65.1 \mathrm{mV}$ \\
Conductances & \\
$\mathrm{Na}_{\mathrm{v}}$ & $1000 \mathrm{nS}$ \\
LVA-K & $200 \mathrm{nS}$ \\
$\mathrm{I}_{\mathrm{h}}$ & $40 \mathrm{nS}\left(\mathrm{E}_{\mathrm{rev}}-43 \mathrm{mV}\right)$ \\
$\mathrm{HVA}-\mathrm{K}$ & $175 \mathrm{nS}$ \\
Leak & $14.5 \mathrm{nS}\left(\mathrm{E}_{\text {rev }}-65 \mathrm{mV}\right)$ \\
Excitatory synaptic parameters & \\
$\mathrm{g}_{\text {Exc }}$ & $50 \mathrm{nS}\left(\mathrm{E}_{\text {rev }} 0 \mathrm{mV}\right)$ \\
Rise time & $0.15 \mathrm{~ms}$ \\
Decay time constant & $0.2 \mathrm{~ms}$ \\
\hline
\end{tabular}

${ }^{a}$ The SBC model properties are as described by Kuenzel et al. (2011) and based on the model by Rothman et al (1993). Ion-channel models are according to Rothman and Manis (2003). The sodium-channel implementation (Rothman et al., 1993) was specifically chosen because of the more rapid recovery from inactivation, which reduces refractoriness of the model SBC and allows it to perform closer to units measured in vivo.

the $\mathrm{Cl}^{-}$-driving force of $20 \mathrm{mV}$ determined by the $\mathrm{V}_{\text {hold }}-\mathrm{E}_{\mathrm{IPSC}}=-71$ to $-50.8 \mathrm{mV}(n=6)$. $\mathrm{E}_{\mathrm{IPSC}}$ was controlled at the beginning of each experiment.

The average depolarization slope was determined from the first derivative, between $20 \%$ and $80 \%$ of the interval from the time point of the current injection to the AP initiation point $\left(\right.$ Depol $\left._{\text {succ }}\right)$, or alternatively to the maximum amplitude of subthreshold depolarization (Depol $\mathrm{f}_{\text {fail }}$ ). The AP initiation was computed from the maximum of the second derivative, representing the time point of the fastest membrane potential increase, estimated as the AP onset.

Post hoc labeling of biocytin-filled neurons with Cy2-conjugated streptavidin was used to morphologically confirm recordings from SBCs (Milenkovic et al., 2009; Dietz et al., 2012). Images were generated with a confocal laser scanning microscope (TCS PS5, Leica).

Statistics. Shapiro-Wilk test (Shapiro and Wilk, 1965) for platykurtic samples, or Shapiro-Francia test (Shapiro and Francia, 1972) for leptokurtic samples were used to determine whether the null hypothesis of Gaussian distribution is a reasonable assumption regarding the data distribution. Assumption of homoscedasticity was tested using Levene's test (Levene, 1960), and datasets were compared with the appropriate $t$ test or ANOVA with post hoc pairwise comparisons (Holm-Sidak test) (Sigma Plot 11, Systat Software). Two-way ANOVA was used to compare the data in Figure 5Ci. Control values before superfusion of strychnine and control values before superfusion of SR95531 were compared for all stimulation frequencies. As there were no differences for a given frequency before drug superfusion, the data were pooled and presented as single control histogram bar for each frequency. Thereafter, the main effect of drug perfusion and possible interaction with input frequency were tested with two-way ANOVA followed by pairwise comparisons (Holm-Sidak test).

Repeated-measures (RM) ANOVA was applied to test for effects of drugs (i.e., before-drug, drug, and after-drug conditions). MannWhitney $U$ test was applied in one case where the data showed skewed non-Gaussian distribution (see Fig. 2A). Data are reported regarding the distribution as mean \pm SEM or median ( 1 quartile, 3 quartile), unless otherwise noted.

Modeling. All simulations were performed with NEURON (Hines and Carnevale, 1997), imported as the module pyNEURON (implemented by Uri Cohen) in Python 2.7.3 under Win7-64bit. The biophysical properties of the SBC model were as previously published (Kuenzel et al., 2011) and in accordance with the model by Rothman et al. (1993). An implementation of the sodium conductance (Rothman et al., 1993) was kindly provided by Marek Rudnicki, TU Munich. Other ion-channel models were identical to those described previously (Rothman and Manis, 2003). The model parameters are represented in detail in Table 1 . The present model also included (1) a somatic compartment, (2) an axon 
hillock/first segment compartment containing all voltage-activated sodium conductances, and (3) a stretch of axon.

Two conductance point processes were attached to the somatic compartment to act as the excitatory endbulb terminal $\left(\mathrm{E}_{\mathrm{rev}}=0 \mathrm{mV}\right)$ and as the combined inhibitory input $\left(\mathrm{E}_{\mathrm{rev}}=-75 \mathrm{mV}\right)$. Conductance traces were pregenerated (see below) and applied to the point processes at the rate of the simulation $(\mathrm{dt}=10 \mu \mathrm{s})$. Conductance templates were fitted to match the rise and decay time constants of recorded waveforms. Excitatory conductances corresponded to the EPSPs recorded in vivo (compare Kuenzel et al., 2011), inhibitory conductances were fitted to IPSC data from slice recordings presented in the study at hand. Temperature differences between the different sources of templates were not taken into account for the simulations.

Rate-dependent plasticity of the inhibitory synaptic mechanism was implemented as a dynamic state-variable that relaxed back to the resting state with double-exponential functions (compare Varela et al., 1997). Exponential parameters of the synaptic plasticity model were as follows: $\mathrm{A}_{\text {fast }} 0.79, \mathrm{~A}_{\text {slow }} 0.99, \tau_{\text {fast }} 31.1 \mathrm{~ms}, \tau_{\text {slow }} 316 \mathrm{~ms}$. Parameters of the decay $\tau$ change were as follows: $\mathrm{A}_{\text {fast }} 8.7, \mathrm{~A}_{\text {slow }} 2.8, \tau_{\text {fast }} 16.9 \mathrm{~ms}, \tau_{\text {slow }} 151 \mathrm{~ms}$, $\tau_{\max } 80 \mathrm{~ms}$. Exponential parameters were extracted by fitting the model results to recorded data. The conductance templates were thereafter convolved with pregenerated spike times to create the conductance traces. Spike times were either single interactions or pulse trains at various frequencies, with the inhibitory input leading excitation by $1 \mathrm{~ms}$. Such a latency was chosen to match the slice experiments investigating the inhibitory potency to suppress spikes evoked by current injection (compare Fig. 2 and 6). Given the nonprimary source of inhibition in the cochlear nucleus, it is conceivable that at some time point the excitatory input will precede the effect of inhibition. However, considering slow decay times of inhibition measured here, at input frequencies in physiological range it is likely that the inhibition overlaps the excitatory conductance. In all other models (see Figs. $8 B$ and 9), inhibition was trailing excitation by $1 \mathrm{~ms}$, to mimic an additional synapse in the inhibitory pathway reaching the SBC. This is based on studies showing that neurons in the deep dorsal cochlear nucleus, which are directly innervated through AN inputs, are probably the major source of inhibition to SBCs (Wickesberg and Oertel, 1990; Xie and Manis, 2013; Campagnola and Manis, 2014). To assess the model performance with in vivo like inputs, spontaneous (silence) and sound-driven (white-noise) spike trains were generated with the help of a simple AN model. This AN model was implemented as a gamma-tone filter bank driving leaky integrate-andfire neurons with noise and refractoriness, using the tools provided by the spiking neural-network simulator "Brian" (Goodman and Brette, 2008). In the absence of sound stimuli, the AN model generates random spike trains with ISI that essentially follow a shifted-exponential distribution. During simulated sound stimulation, the model generates phase-locked, AN-like spike trains.

In the model, we also implemented a more realistic representation of the excitatory endbulb synapse. Numerous in vitro studies showed prominent short-term synaptic depression, occurring also in preparations from older animals (Wang and Manis, 2008; Yang and Xu-Friedman, 2009; Wang et al., 2010). Analogous to our approach for the inhibitory synaptic plasticity, a phenomenological model was fitted to pulse-train data presented in respective studies. Data for 100, 200, 300, and $333 \mathrm{~Hz}$ trains were used and the mean results of these fits were taken as model parameters. A depression state variable was reduced by every event and relaxed back to rest with a double exponential function $\left(\mathrm{A}_{\text {fast }} 0.75, \mathrm{~A}_{\text {slow }}\right.$ $\left.0.94, \tau_{\text {fast }} 17.2 \mathrm{~ms}, \tau_{\text {slow }} 57.0 \mathrm{~ms}\right)$. The maximal endbulb conductance was multiplied with the state variable to derive the excitatory conductance active at a given time. Maximal endbulb conductance of $75 \mathrm{nS}$ was used to counteract tonic depression by spontaneous activity in the model. As shown previously by Pliss et al. (2009), endbulb conductances measured in vitro can span a large range of values, with $75 \mathrm{nS}$ being toward the lower end.

As the short-term depression at the endbulb synapse may not play such a prominent role in the adult auditory brainstem in vivo (Borst, 2010; Crins et al., 2011; Kuenzel et al., 2011), a nondepressing stochastic endbulb model synapse was also included. Here, the EPSG amplitude for every event was drawn from a normal distribution with a SD of \pm 0.2 around the mean, which led to an average EPSG of $48.9 \pm 9.8 \mathrm{nS}$.

Interaction of the excitatory and inhibitory conductance in the SBC model was scrutinized by simulating the membrane potential response of the recorded SBC. All experiments were simulated at $35^{\circ} \mathrm{C}$.

\section{Results \\ Inhibition attunes the in vivo input-output rate at the endbulb of Held synapse}

To evaluate the impact of acoustically evoked inhibition on AP generation in SBCs, we used pure tone stimulation within the unit's high-frequency inhibitory sideband. The presently recorded units were located in the rostral AVCN, had low CFs (median 2.0 [first quartile 1.39, third quartile 2.24] $\mathrm{kHz}, n=16$ ), primary-like response patterns, and three-component complex spike waveforms. Together, these characteristics identify them as large SBCs (Tolbert et al., 1982; Rouiller and Ryugo, 1984; Hackney et al., 1990; Ostapoff et al., 1994; Bazwinsky et al., 2008; Englitz et al., 2009). The average spontaneous firing rate was $53.5 \pm 17.2 \mathrm{~Hz}$ and thresholds ranged from -8.1 to $63.3 \mathrm{~dB}$ SPL (median 12 [first quartile 5.9, third quartile 30.2] dB).

The juxtacellular recorded voltage signals from each SBC were divided into two categories, based on principal component analysis complemented by hierarchical clustering (see also Englitz et al., 2009, Typlt et al., 2010): (1) three components signals (P-A-B), i.e., signals containing a discernable postsynaptic AP $\left(\mathrm{EPSP}_{\text {succ }}\right)$; and (2) signals composed of the components 'P' and 'A,' but lacking ' $\mathrm{B}$,' i.e., signals representing only the endbulb discharge and the postsynaptic EPSP (EPSP fail $)$ (Fig. 1A).

Typically, the acoustically evoked response profiles of SBCs show inhibitory sidebands flanking the excitatory response areas (Fig. 1B). The respective excitatory and inhibitory domains were determined as frequency-intensity ranges in which the discharge rates were significantly increased/reduced compared with the spontaneous firing rate ( $p<0.01$, two-sample $t$ test). The inhibitory sidebands spanned the frequency range $0.75-1.9$ octaves above unit's CF (mean $\pm \mathrm{SD}=1.27 \pm 0.4 \mathrm{O}, n=16$ ). Acoustically evoked inhibition was elicited by a tone burst stimulation at 4.8 [first quartile 4, third quartile 4.9] $\mathrm{kHz}$ and $44 \pm 15 \mathrm{~dB}$ SPL, $n=16$ (Fig. $1 B$ ). Under these conditions, the incidence of failures of postsynaptic spikes was significantly increased $\left(\mathrm{EPSP}_{\text {fail }}\right)$ with respect to spontaneous activity (Fig. $1 C, D ; \mathrm{EPSP}_{\text {fail }} /\left(\mathrm{EPSP}_{\text {fail }}+\right.$ $\left.\mathrm{EPSP}_{\text {succ }}\right)=0.61 \pm 0.19$ vs $0.27 \pm 0.13, p<0.001$, paired $t$ test $)$. Notably, such acoustic stimulation did not change the overall input to the SBC, as indicated by the constant overall EPSP rate. This excludes the possibility that a smaller incidence of postsynaptic APs is due to a reduced ANF input (Fig. 1D; EPSP = EPSPsucc $+\mathrm{EPSP}_{\text {fail }}, 10-90 \mathrm{~ms}$ vs $150-230 \mathrm{~ms}, p=0.34$, paired $t$ test) (further elaborated in Fig. 8A). These in vivo data demonstrate that acoustically evoked inhibition can control the fidelity of signal transmission at the endbulb of Held synapse by engaging postsynaptic mechanisms while leaving the presynaptic calyceal input unaffected.

\section{Synaptic inhibition prevents the AP generation}

Generally, $\mathrm{GABA}_{\mathrm{A}}-\mathrm{R}$ and glycine-R mediated inhibition in mammalian neurons is achieved by both shunting (i.e., reduction of the amplitude of EPSPs due to a local reduction of the input resistance in the vicinity of excitatory synapses) and membrane hyperpolarization (i.e., moving the membrane potential away from the action potential threshold). Accordingly, increased occurrence of postsynaptic AP failures during acoustic stimulation might be attributable to the inhibitory transmission interfering 
with conductance generated by the calyceal excitatory inputs. To assess such potential interaction, the waveforms of SBC signals recorded in vivo during acoustic stimulation within the inhibitory sidebands were analyzed and compared with the respective signals recorded during spontaneous activity (Fig. 2A). Under both conditions, the EPSP-to-AP transition times were negatively correlated with the EPSP rising slopes, i.e., the more shallow the slopes the longer the EPSP-to-AP transition times (spontaneous $r_{s}=-0.56$, $p<0.001$; inh. $\left.\mathrm{r}_{\mathrm{s}}=-0.55, p<0.001\right)$ (Fig. 2B, left). Yet, the EPSP-to-AP transition time was significantly longer and rising slopes flattened during stimulation in the units' acoustic sidebands (Fig. 2A, $B$; delay: $p<0.01$ in 16 of 16 neurons, slope: $p<0.05$ in 10 of 16 neurons, MannWhitney $U$ test). From these results, it can be concluded that the inhibition reduces the slope steepness of the membrane potential depolarization, which was shown to be crucial for successful AP generation in SBCs (McGinley and Oertel, 2006).

Postnatal development of the chloride homeostasis in SBCs renders inhibitory transmission hyperpolarizing before the onset of acoustic information processing (Milenkovic et al., 2007). To assess the potency of hyperpolarizing inhibition to impair the AP generation, gramicidin perforated-patch recordings were conducted in brainstem slices during the stimulation of synaptic inputs in combination with suprathreshold depolarizing current injections that, when presented alone, elicited a single action potential.

Evoked IPSPs were hyperpolarizing from $\mathrm{V}_{\text {rest }}$ by $-5.6 \pm 1.0 \mathrm{mV}$ $(n=6)$ (Fig. 2C, middle). Similar hyperpolarizations were observed in whole-cell recordings with $\mathrm{Cl}^{-}$pip $=5 \mathrm{~mm}$, the estimated chloride concentration in SBCs around hearing onset (Milenkovic and Rübsamen, 2011) (Fig. $2 D$, middle; $\Delta \mathrm{V}_{\mathrm{m}}=$ $-6.4 \pm 0.7 \mathrm{mV}, n=16 ; p=0.54$ for whole-cell vs gramicidin perforated patch, $t$ test). Under both recording conditions, larger synaptically evoked hyperpolarizations correlated with AP fail-

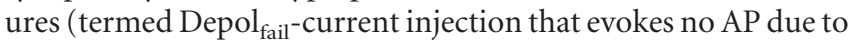
synaptic inhibition) (Fig. $2 C, D$, right). The amplitude of hyperpolarization $\left(\Delta \mathrm{V}_{\mathrm{m}}\right)$ was linearly related to the depolarization rising slope (Fig. $2 E$; mean $r=0.94 \pm 0.01, p<0.001$ for each cell, $n=8$ ). Thus, the synaptically evoked inhibition flattens the depolarization slope rate and has, therefore, the comparable effect to acoustic stimulation within inhibitory sidebands in vivo. Together, our data obtained in vivo and in slice recordings are consistent with earlier studies by showing that the inhibitory inputs have the potency to suppress the AP generation in SBCs (Caspary et al., 1994; Gai and Carney, 2008; Dehmel et al., 2010; Xie and Manis, 2013).

\section{Surprisingly slow kinetics of inhibitory transmission}

To assess the properties of inhibitory synaptic transmission onto identified SBCs (Fig. 3A), eIPSCs were recorded at different input
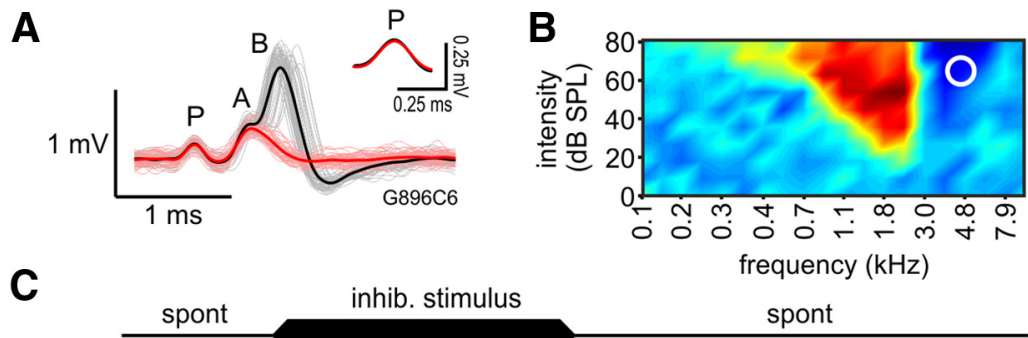

Figure 1. Acoustic stimulation within the inhibitory sideband increases the AP failure rate. $A$, Representative extracellular recording from the SBC (unit G896C6) showing a complex signal waveform consisting of a prepotential (P), EPSP (A), and action potential (AP) (B) (gray signals). Some EPSPs fail to trigger an AP (light red signals). Black and red lines indicate the mean response area ( $\mathrm{CF}=2.24 \mathrm{kHz}$, threshold $=7.5 \mathrm{~dB} \mathrm{SPL}$ ) exhibits a pronounced inhibitory sideband with reduced discharge rate (EPSP fail, $_{\text {, }}$ red dots) differs from the spontaneous activity (spont). Note the increased incidence of

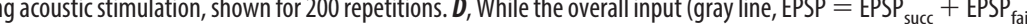
emains constant, the number of EPSP fail increases during inhibitory stimulation, thus changing the relative fractions of EPSP fail and APs. $\boldsymbol{E}$, Incidence of EPSP fail increases from $20 \%$ (spont) to $60 \%$ (inhib. stimulus) with slow onset/offset dynamic. frequencies (Fig. 3B). The baseline-to-peak amplitude of single events ranged from -132 to $-1164 \mathrm{pA}$, with a mean $\pm \mathrm{SD}=$ $-494.8 \pm 270.2 \mathrm{pA}, n=43$. Comparison across the cells yielded neither a correlation between the IPSC rise time and amplitude $\left(\mathrm{r}_{\mathrm{s}}=0.04, p=0.78, n=43\right)$ nor between decay time and amplitude $\left(r_{s}=-0.13, p=0.41, n=43\right)$. Also, no systematic variation was seen across the ages (P22-P33) with respect to current decay times $\left(r_{s}=-0.07, p=0.91\right)$, rise times $\left(r_{s}=-0.23, p=0.14\right)$, and amplitudes $\left(r_{s}=0.25, p=0.11\right)$. The single-event eIPSCs exhibited remarkably slow synaptic decays $\left(\tau_{\mathrm{w}}=23.7 \pm 5.3 \mathrm{~ms}\right.$; $10 \%-90 \%$ rise time $=0.46 \pm 0.18 \mathrm{~ms}, n=43)$, compared with decay rates measured from neurons in the superior olivary complex (Awatramani et al., 2004; Magnusson et al., 2005; Fischl et al., 2012; Stange et al., 2013; Kramer et al., 2014). Furthermore, the synaptically evoked hyperpolarization under gramicidinperforated-patch condition had also a slow decay time constant $\left(\tau_{\mathrm{w}}=18.5 \pm 4.0 \mathrm{~ms}, n=6\right)$. Thus, repetitive stimulation caused a current summation in consecutive events. At $10 \mathrm{~Hz}$ stimulation, the first event had on average the highest conductance (calculated from $\mathrm{I}_{\text {baseline }}$ ), whereas for frequencies $50-333 \mathrm{~Hz}$ the maximal total conductance was reached between IPSC pulses 7-9 (Fig. 3C; maximum $g_{\text {inh }} 10 \mathrm{~Hz}=22.1 \pm 3.1 \mathrm{nS}, n=7 ; 50 \mathrm{~Hz}=36.7 \pm 3.3$ $\mathrm{nS}, n=7 ; 100 \mathrm{~Hz}=51.3 \pm 3.2 \mathrm{nS}, n=24$; and $333 \mathrm{~Hz}=68.0 \pm$ $5.4 \mathrm{nS}, n=12$ ). Because of frequency-dependent current sum- 

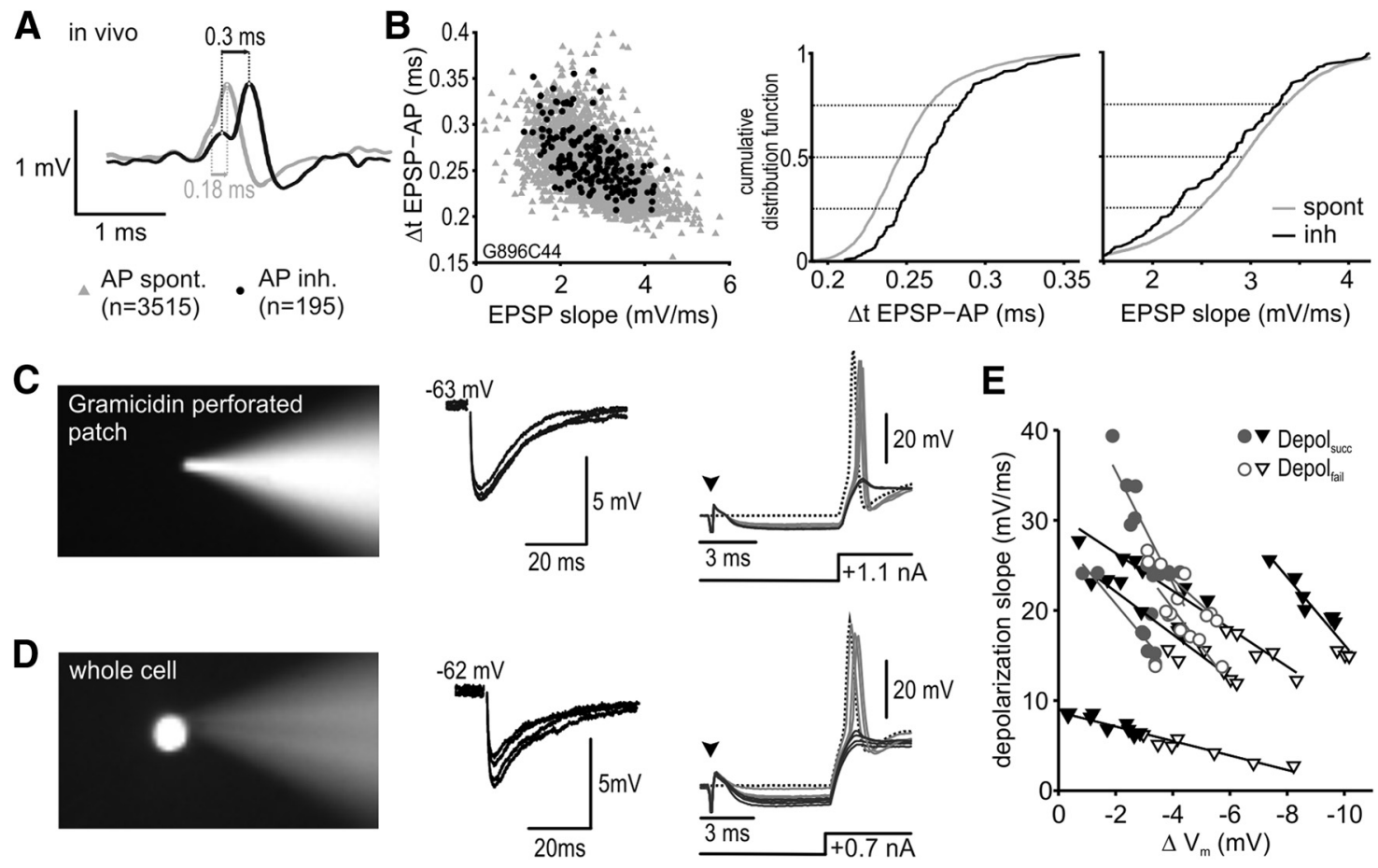

Figure 2. Hyperpolarizing inhibitory input suppresses AP generation. $A$, Mean waveforms of in vivo recording in the absence of acoustic stimulation (gray, 3515 signals from a single SBC) and during stimulation in the units' inhibitory sideband (black, 195 signals). $\boldsymbol{B}$, Left, Negative correlation between the EPSP rising slope and the EPSP-to-AP transition time. Gray and black symbols represent spontaneous activity and inhibitory stimulation, respectively (spont. $r_{s}=-0.56, p<0.001$; inh. $r_{s}=-0.55, p<0.001$ ). The spontaneous events show larger variability, but the cumulative distribution function indicates their skewness toward shorter EPSP-to-AP times ( $\boldsymbol{B}$, middle; $p<0.001$, Mann-Whitney $U$ test) and steeper EPSP rising slopes ( $\boldsymbol{B}$, right; $p=0.002$, Mann-Whitney $U$ test). $\boldsymbol{C}, \boldsymbol{D}$, Inhibitory synaptic inputs are hyperpolarizing in gramicidin perforated-patch $(\boldsymbol{C})$ and whole-cell recordings with $\left[\mathrm{Cl}^{-}\right]_{\mathrm{pip}}=5 \mathrm{~mm}(\boldsymbol{D})(\mathrm{middle}$ traces). Depending on the strength of synaptically evoked hyperpolarization through stimulation of the inhibitory input, AP failures occurred in response to suprathreshold current injection (right traces, gray lines).

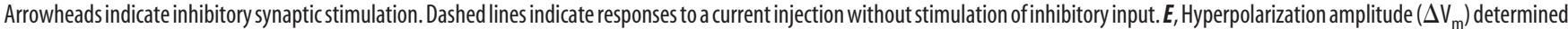
the average depolarization slope, both for isolated depolarizations (Depol $\left.\right|_{\text {fail }}$ open symbols) and for depolarizations followed by an AP (Depol ${ }_{\text {succ }}$ filled symbols). The data are similar for gramicidin perforated-patch $(n=4)$ (gray) and whole-cell recordings $(n=4)$ (black).

mation, the average amplitude of the last three IPSCs in a 50pulse train increased fourfold between 10 and $333 \mathrm{~Hz}(10 \mathrm{~Hz}=$ $-0.26 \pm 0.03 \mathrm{nA} ; 333 \mathrm{~Hz}=-1.01 \pm 0.08 \mathrm{nA}, p<0.001)$.

Analysis of the phasic peak currents ( $\mathrm{I}_{\text {peak }}$, Fig. $3 B$, inset) revealed a prominent frequency-dependent depression (Fig. $3 D$; normalized mean $40-50$ th $\mathrm{I}_{\text {peak }} 10 \mathrm{~Hz}=0.58 \pm 0.05, n=7 ; 50$ $\mathrm{Hz}=0.35 \pm 0.03, n=7 ; 100 \mathrm{~Hz}=0.18 \pm 0.02, n=24 ; p<0.001$, ANOVA). The prolongation of consecutive synaptic currents is demonstrated by $\tau_{\mathrm{w}}$ values of the last event in a $100 \mathrm{~Hz}$ train (Fig. $3 E ; \tau_{\mathrm{w}} 1 \mathrm{st}=23.1 \pm 0.7 \mathrm{~ms}, 5 \mathrm{th}=44.3 \pm 3.3 \mathrm{~ms}, 10 \mathrm{th}=54.3 \pm$ $4.6 \mathrm{~ms}$, 20th $=62.9 \pm 4.6 \mathrm{~ms}$, 30th $=68.4 \pm 6.0 \mathrm{~ms}$, 40th $=$ $73.2 \pm 5.3 \mathrm{~ms}, 50 \mathrm{th}=71.7 \pm 3.7 \mathrm{~ms} ; n=6$ ). Analogously, the current decay also showed a frequency-dependent prolongation of the last IPSC (Fig. $3 F$; mean $\tau_{\mathrm{w}} 50$ th $0.1 \mathrm{~Hz}=25.1 \pm 2.2 \mathrm{~ms} ; 10$ $\mathrm{Hz}=30.8 \pm 2.6 \mathrm{~ms} ; 20 \mathrm{~Hz}=40.6 \pm 1.5 \mathrm{~ms} ; 50 \mathrm{~Hz}=52.5 \pm 3.6$ $\mathrm{ms} ; 100 \mathrm{~Hz}=67.7 \pm 2.7 \mathrm{~ms} ; 200 \mathrm{~Hz}=79.3 \pm 2.7 \mathrm{~ms}$; and 333 $\mathrm{Hz}=77.6 \pm 4.4 \mathrm{~ms} ; n=6)$. The maximum decay time was reached at $200 \mathrm{~Hz}$ with no further increase toward higher stimulus frequency. In summary, these data indicate activity-dependent buildup of inhibitory conductance due to slow current decay. Furthermore, a synaptic depression shapes the current profile during ongoing inhibitory activity.

GABA enhances and slows down the predominantly glycinergic inhibition

To determine the contribution of transmitters involved in synaptic inhibition, eIPSCs were pharmacologically characterized by superfusion of glycine- $\mathrm{R}$ and $\mathrm{GABA}_{\mathrm{A}}-\mathrm{R}$ antagonists. First, the specificity of antagonists at the concentrations used was confirmed in control experiments. The currents evoked by focal puff application $(5 \mathrm{~ms})$ of either glycine or GABA were efficiently blocked by strychnine and SR95531, respectively (Fig. 4A; $\mathrm{I}_{\text {glycine }}$ $0.5 \mathrm{mM}=-1.67 \pm 0.12 \mathrm{nA},+$ strychnine $0.5 \mu \mathrm{M}=-0.08 \pm 0.02$ $\mathrm{nA}, n=6, p<0.001$, paired $t$ test; $\mathrm{I}_{\mathrm{GABA}} 0.5 \mathrm{mM}=-1.23 \pm 0.36$ $\mathrm{nA},+$ SR95531 $20 \mu \mathrm{M}=-0.01 \pm 0.007 \mathrm{nA}, n=5, p<0.001$, paired $t$ test).

While SR95531 $(20 \mu \mathrm{M})$ did not affect the $\mathrm{I}_{\text {glycine }}$ amplitude (Fig. $4 C ; p=0.28, n=6$, ANOVA followed by pairwise comparisons), the current was progressively blocked by increasing strychnine concentrations, achieving maximal inhibition at $1 \mu \mathrm{M}$ $(98.8 \pm 0.38 \%, n=6)$ (Fig. $4 B, C)$. The effect of strychnine was reversible, again reaching $93 \%$ of the initial $I_{\text {glycine }}$ after a washout of $30 \mathrm{~min}$ (Fig. $4 B$ ). Similarly, strychnine concentrations of 0.5 and $1 \mu \mathrm{M}$ had no effect on $\mathrm{I}_{\mathrm{GABA}}$ (Fig. $4 D ; p=0.99$ for 0.5 vs $1 \mu \mathrm{M}$, ANOVA). Hence, it was concluded that, at the concentrations used, strychnine and SR95531 specifically blocked the respective glycine and GABA evoked currents. Further corroboration was provided by showing equal inhibitory potency of increasing SR95531 concentrations on eIPSCs (Fig. 4E; eIPSC $=-0.52 \pm$ $0.05 \mathrm{nA}, n=17 ;+\mathrm{SR} 9553110 \mu \mathrm{M}=-0.40 \pm 0.07 \mathrm{nA}, 82 \pm 2 \%$ of control, $n=6$; + SR95531 $20 \mu \mathrm{M}=-0.43 \pm 0.05 \mathrm{nA}, 84 \pm 3 \%$ of control, $n=11 ; p=0.89$ for 10 vs $20 \mu \mathrm{M}$ SR95531, ANOVA). Similar effects of SR95531 were observed on spontaneous IPSCs, suggesting that the $\mathrm{GABA}_{\mathrm{A}}-\mathrm{R}$ contribution is an intrinsic property of inhibitory synapses and not a result of synaptic stimulation (Fig. 4E; sIPSC $=-40.6 \pm 3.6 \mathrm{pA}$, +SR95531 $20 \mu \mathrm{M}=$ 
$-33.8 \pm 2.7 \mathrm{pA}, 84 \pm 4 \%$ of control, $n=$ $5, p=0.03$, paired $t$ test). Based on these data, it seems unlikely that, in our experiments, $20 \mu \mathrm{M}$ SR95531 acted as a lowaffinity antagonist of glycine receptors (Beato et al., 2007).

After validating the specificity of antagonists, the contribution of both glycine and $\mathrm{GABA}_{\mathrm{A}}$ receptors to IPSCs was quantified (Fig. 5). The currents were differentially affected by $0.5-1 \mu \mathrm{M}$ strychnine and $20 \mu \mathrm{M}$ SR95531 (Fig. 5A). The glycinergic component, measured under SR95531, dominated the peak amplitude (Fig. $5 A, B$; single or first eIPSC: control = $-0.60 \pm 0.09 \mathrm{nA},+$ SR95531 $=-0.44 \pm$ $0.05 \mathrm{nA}, p<0.01$; average of 7-9th baseline IPSCs at $100 \mathrm{~Hz}$ : control $=-1.06 \pm$ $0.10 \mathrm{nA},+$ SR95531 $=-0.89 \pm 0.07 \mathrm{nA}$, $p<0.05$; average of $48-50$ th baseline IPSCs at $100 \mathrm{~Hz}$ : control $=-0.59 \pm 0.08$ $\mathrm{nA},+\mathrm{SR} 95531=-0.49 \pm 0.06 \mathrm{nA}, p=$ $0.12 ; n=15$; paired $t$ test). Yet, the initially small GABAergic component conspicuously increased from $5 \pm 1 \%$ to $12 \pm 3 \%$ during ongoing $100 \mathrm{~Hz}$ activity (single: control $=-0.65 \pm 0.12 \mathrm{nA}$, + strychnine $0.5-1 \mu \mathrm{M}=-0.04 \pm 0.02 \mathrm{nA}$, $p=0.001 ; 7-9$ th baseline IPSCs: control $=$ $-1.11 \pm 0.14 \mathrm{nA},+$ strychnine $0.5-1 \mu \mathrm{M}=$ $-0.09 \pm 0.01 \mathrm{nA}, p<0.001 ; 48-50$ th baseline IPSCs: control $=-0.55 \pm 0.13 \mathrm{nA}$, + strychnine $0.5-1 \mu \mathrm{M}=-0.06 \pm 0.01 \mathrm{nA}$, $p<0.01 ; n=7$, paired $t$ test).

Synaptically released GABA not only contributed to the IPSC amplitude, but it also prolonged the current kinetics in an activity-dependent manner (Fig. 5C). The decays of cotransmission, glycinergic, and GABAergic eIPSCs were similar for single events $\left(\tau_{\mathrm{w}}\right.$ : control $=25.7 \pm 1.2 \mathrm{~ms}, n=$ 25; +SR95531 $20 \mu \mathrm{M}=23.2 \pm 1.2 \mathrm{~ms}$, $n=13 ;+$ strychnine $1 \mu \mathrm{M}=26.2 \pm 3.2$ ms, $n=12, p>0.5$, two-way ANOVA followed by Holm-Sidak test). However, the differences became evident at higher input frequencies (interaction of frequency and drug superfusion $p=0.02$ ). At $100 \mathrm{~Hz}$, control IPSCs had time constants between the fast glycinergic and slow GABAergic currents (Fig. 5Ci; $\tau_{\mathrm{w}}$ 50th: control $=64.2 \pm 2.1 \mathrm{~ms}, n=25 \mathrm{vs}$ + SR9553120 $\mu \mathrm{M}=56.3 \pm 2.8 \mathrm{~ms}, n=$ $14, p<0.05$; control vs + strychnine $1 \mu \mathrm{M}=$ $81.1 \pm 6.4 \mathrm{~ms}, n=11, p<0.001$, two-way ANOVA followed by Holm-Sidak test). Notably, the kinetics of control events at $333 \mathrm{~Hz}$ was similar to isolated GABAergic IPSCs $\left(\tau_{\mathrm{w}}\right.$ 50th: control $=76.9 \pm 2.7 \mathrm{~ms}$, $n=21$ vs + SR95531 $20 \mu \mathrm{M}=65.6 \pm 3.5$ ms, $n=10, p<0.05$; control vs + strychnine $1 \mu \mathrm{M}=84.1 \pm 5.3 \mathrm{~ms}, n=11, p=$ 0.11 , two-way ANOVA with post hoc
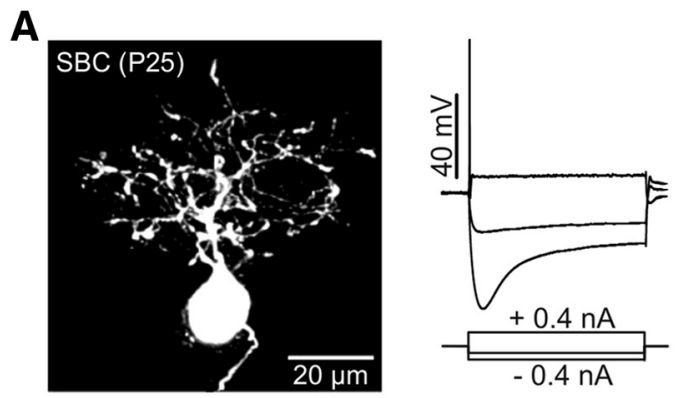

B
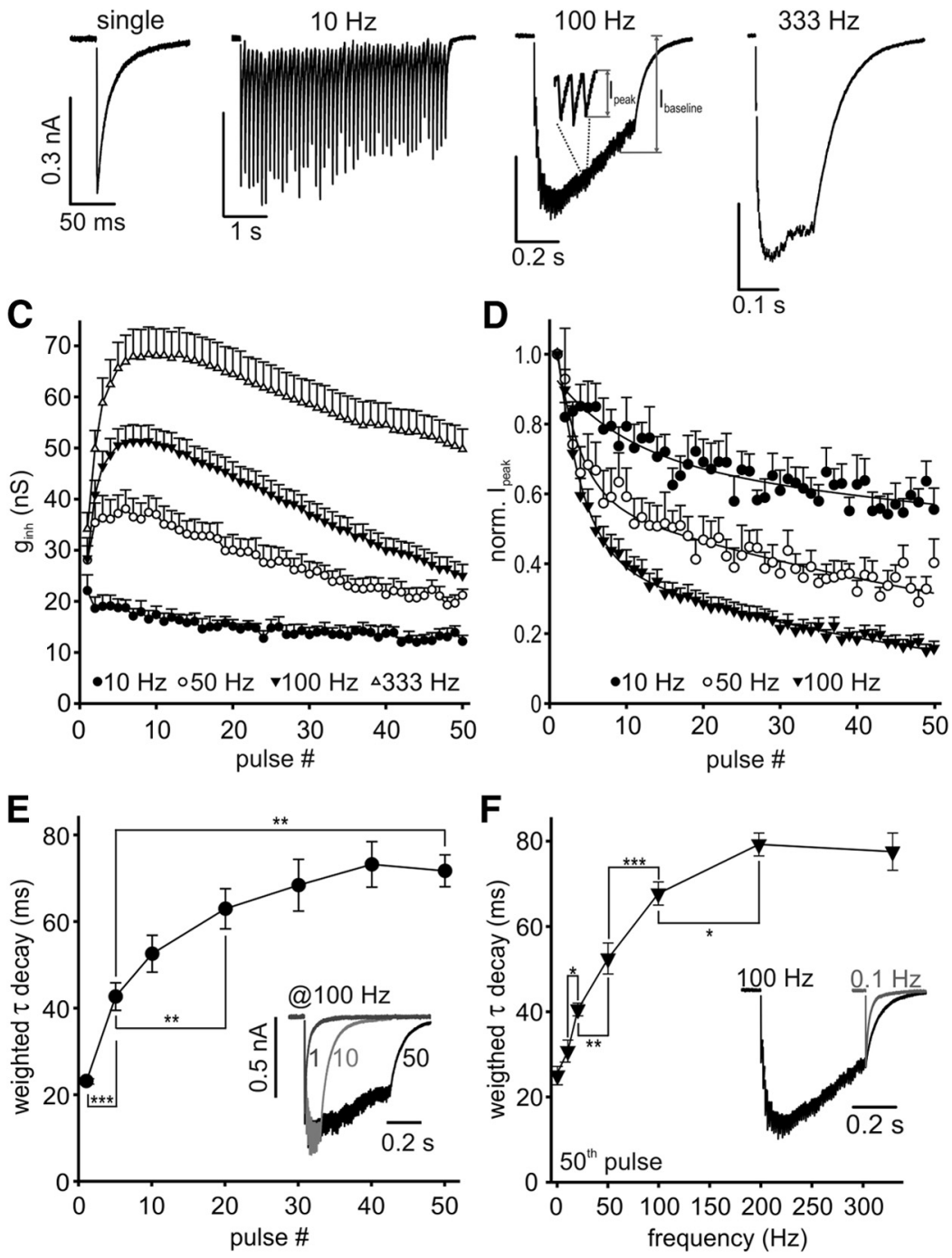

Figure 3. Slow inhibitory transmission on SBCS.A, Post hoc labeling of biocytin-filled SBC shows the characteristic morphology (left). Typical SBC responses to positive/negative current injections. Phasic firing and hyperpolarization that sags back toward rest (right). $\boldsymbol{B}$, Exemplary traces of elPSCs recorded at different stimulation frequencies (single and 50 pulses at 10, 100, and $333 \mathrm{~Hz}$ ). $I_{\text {baseline, }}$ Difference between the baseline before stimulation and the peak amplitude of each event; $I_{\text {peak }}$ difference between the steady state and the peak of the successive event (enlarged trace shown as inset for $100 \mathrm{~Hz}$ ). C, Frequency-dependent buildup of inhibitory conductance $\left(g_{\text {inh }}\right)$, calculated from $\mathrm{I}_{\text {baseline }}(10 \mathrm{~Hz}$ and $50 \mathrm{~Hz}, n=7 ; 100 \mathrm{~Hz}, n=24$; and $333 \mathrm{~Hz}, n=12)$. D, Mean normalized peak currents $\left(\mathrm{l}_{\text {peak }}\right)$ during trains of 50 pulses at different frequencies ( $10 \mathrm{~Hz}$ and $\left.50 \mathrm{~Hz}, n=7 ; 100 \mathrm{~Hz}, n=24\right)$. Comparison of the $\mathrm{I}_{\text {peak }}$ averaged between the pulses $40-50: 10$ versus $50 \mathrm{~Hz}, p<0.05 ; 50$ versus $100 \mathrm{~Hz}, p<0.001$, ANOVA. $\boldsymbol{E}$, Ongoing activity prolongs the mean weighted time constant of the IPSCS. $\tau$ decay was calculated from peak to baseline of the last event in $100 \mathrm{~Hz}$ trains consisting of different stimulus numbers. $\boldsymbol{F}$, Frequency-dependent extension of the last IPSC in a 50-pulse train. IPSC obtained at $0.1 \mathrm{~Hz}$ (gray) was normalized to the last (50th, black) IPSC in a $100 \mathrm{~Hz}$ train to depict the differences in kinetics (inset). $\boldsymbol{E}, \boldsymbol{F}^{*} p<0.05,{ }^{* *} p<0.01,{ }^{* * *} p<0.001$ (RM ANOVA). $n=6$. 
A

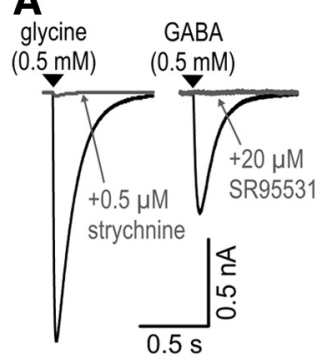

B
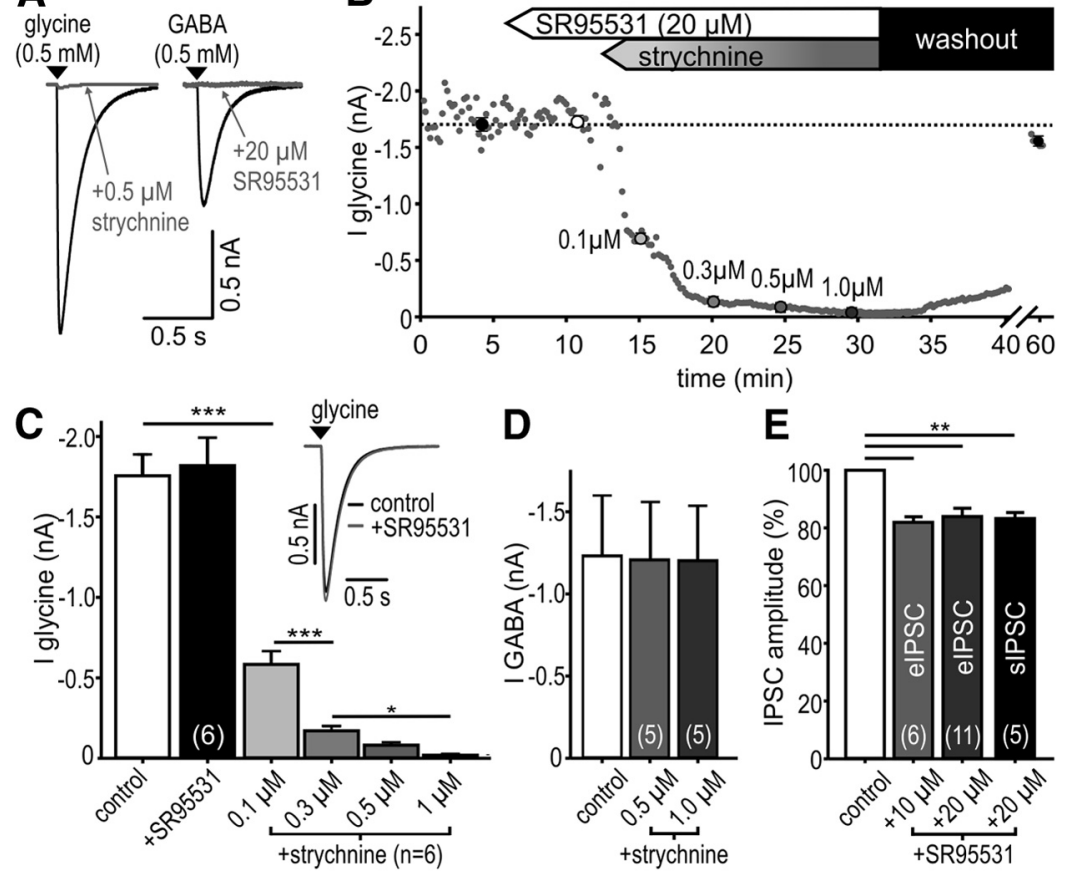

Figure 4. Pharmacology of glycine and $\mathrm{GABA}_{\mathrm{A}}$ receptors. $A$, Whole-cell currents evoked by a $5 \mathrm{~ms}$ pressure application of glycine or GABA (black). Bath application of $0.5 \mu \mathrm{m}$ strychnine or $20 \mu \mathrm{m}$ SR95531 blocked the responses by $95 \%$ and $99 \%$, respectively (gray). Arrowheads indicate the time point of agonist application. B. Glycine-evoked currents were not affected by SR95531 but efficiently blocked by strychnine. The complete block of $\mathrm{I}_{\text {glycine }}$ with $1 \mu \mathrm{m}$ strychnine was reversible (washout). C, Summary of SR95531 (20 $\mu \mathrm{M})$ and strychnine effects on $\mathrm{I}_{\text {glycine. }}$. Glycine-induced current is not affected by a bath application of SR95531 (black bar and inset). The significant inhibition by increasing strychnine concentrations. ${ }^{*} p<0.05$ (ANOVA). ${ }^{* * *} p<0.001$ (ANOVA). D, Currents evoked by GABA $(0.5 \mathrm{~mm})$ were not affected by high strychnine concentrations. The experiment was done in the presence of (GP55845 (3 $\mu \mathrm{M}$ ). Error bars indicate mean \pm SEM; $n=5 . p=0.99$ (ANOVA). $E$, Both 10 and $20 \mu \mathrm{m}$ SR95531 had similar inhibitory effects on synaptically evoked (eIPSC) and spontaneous (sIPSC) event amplitudes. Cell numbers are given in parentheses. ${ }^{* *} p<0.01$ (ANOVA).

Holm-Sidak test). Together, these results demonstrate that GABA progressively slows the inhibition with increasing rates of activity. GABA-mediated prolongation of inhibitory synaptic events was also shown for other central synapses (Jonas et al., 1998; Nabekura et al., 2004; Apostolides and Trussell, 2013). The eIPSC rise times were similar for dual glycine-GABA and for pharmacologically isolated events $(10-90 \%$ rise time control $=$ $0.42 \pm 0.05 \mathrm{~ms},+$ strychnine $=0.46 \pm 0.05 \mathrm{~ms}, n=7, p=0.63$; control $=0.49 \pm 0.03 \mathrm{~ms},+$ SR95531 $=0.48 \pm 0.03 \mathrm{~ms}, n=14$, $p=0.60$, paired $t$ test for both). Thus, given the rapid and similar onset of all inhibitory currents, it is unlikely that the slow decay kinetics are due to dendritic filtering or space clamp issues.

\section{GABA increases the potency of inhibition}

The in vivo results demonstrate that acoustically evoked inhibition can constrain AP firing in SBCs. By means of slice recordings, we showed that the inhibitory potency is enhanced by the synergistic action of glycine and GABA. Next we investigated how each of the two inhibitory mechanisms interferes with AP generation. Under current-clamp, the APs were elicited by a $5 \mathrm{~ms}$ current injection set slightly over the threshold to reliably evoke APs during a $100 \mathrm{~Hz}$ train (Fig. 6A, AP probability of 1 in Fig. $6 E$ ). Concurrent stimulation of inhibitory synaptic input (10 pulses at $100 \mathrm{~Hz}$, each pulse presented $5 \mathrm{~ms}$ before corresponding depolarizing current injection) reliably blocked the generation of APs. This block outlasted the duration of inhibitory stimulation by $45 \pm 3 \mathrm{~ms}(n=12)$, consistent with the prolonged efficacy of inhibition (Fig. 6B,F). The duration of this inhibitory after-effect is comparable with the $\tau_{\mathrm{w}}$ of $54.3 \pm 4.6$ $\mathrm{ms}$, measured for the 10th eIPSC at 100 $\mathrm{Hz}$ (compare Fig. 3E). This implies that the slow decay of inhibition can account for the failures in AP firing.

Application of $0.5 \mu \mathrm{M}$ strychnine completely abolished the inhibition of APs (Fig. $6 C$ ). Blocking $\mathrm{GABA}_{\mathrm{A}}-\mathrm{R}$ had a more subtle effect: The AP inhibition was delayed and lost its potency faster after the end of inhibitory stimulation (Fig. 6D). Figure $6 E, F$ demonstrates the prolonged poststimulation inhibitory effect of the glycine-GABA coinhibition with respect to the sole glycinergic inhibition. Summary data in Figure $6 E$ show that the time when the first AP occurs is significantly longer after full, compared with pharmacologically isolated glycinergic, inhibition. Although the GABAergic component had such a prominent effect on capacity of inhibition, it just moderately contributed to the membrane hyperpolarization evoked by stimulation of synaptic inputs. Figure $6 G$ summarizes the relative contribution of each transmitter component to total hyperpolarization $\left(\Delta \mathrm{V}_{\mathrm{m}}\right.$ single: control $=$ $6.6 \pm 0.9 \mathrm{mV},+$ SR95531 $=-5.0 \pm 0.6$ $\mathrm{mV}, n=9, p=0.011$; control $=-6.1 \pm$ $1.1 \mathrm{mV},+$ strychnine $=-0.19 \pm 0.1$ $\mathrm{mV}, n=7, p=0.002$; 10 th at $100 \mathrm{~Hz}$ : control $=-15.3 \pm 1.3 \mathrm{mV}$, + SR95531 $=-12.7 \pm 1.1 \mathrm{mV}, n=13$, $p<0.001$; control $=-9.9 \pm 1.0 \mathrm{mV}$, + strychnine $=0.65 \pm 0.3 \mathrm{mV}, p<0.001, n=7$; paired $t$ test for all). These data are in agreement with the results from voltage-clamp experiments (Fig. $4 E$ ). Although synaptically released GABA seems not capable of preventing the AP generation per se, it appears necessary to adjust the duration of AP inhibition through a synergistic action with glycine.

\section{Interaction of excitation and inhibition in silico}

These results give rise to the question of how efficient the slow inhibition is in preventing calyceal inputs from triggering APs considering a wider range of physiologically relevant conductances. To get a closer insight into the inhibitory impact on the powerful and fast excitatory synaptic conductance (i.e., endbulblike excitation), we performed in silico experiments. The model inhibitory synaptic conductance was matched to the data from slice recordings. Simulating synaptic currents without considering the plasticity and rate-dependent reduction of conductance (e.g., $23.8 \mathrm{nS}$ initial conductance and fixed $24 \mathrm{~ms}$ decay timeconstant) only poorly matched the data measured in vitro (Fig. $7 A$, compare Fig. $3 C$ ). A better match of the current profile was achieved after including the rate-dependent increase of $\tau$ decay (Fig. $3 F$ ), which counteracts depression during the stimulus train by facilitating summation. Conductance waveforms underlying the synaptic model mechanism are shown in Figure $7 B$. The respective conductance values for glycine and GABAergic components were implemented in the model, whereas other aspects, such as onset and decay time-constants, were simulated as identical for both parts. 
Referring to the data from slice experiments, the interactions between inhibition and excitation were assessed for 100 $\mathrm{Hz}$ trains. Initially, a simplified excitatory input with fixed conductance was used for simulations (Figs. 7 and 8) despite the fact that short-term plasticity of the endbulb of Held synapse has been demonstrated in many studies (Bellingham and Walmsley, 1999; Wang and Manis, 2008; Yang and Xu-Friedman, 2008). As these particular experiments aimed to assess the interaction of the two inhibitory transmitters and their effect on AP firing, the model was simplified by investigating the dynamics of inhibition acting on a constant excitation. These data are directly comparable to the results in Figure 6, which also had a constant strength of excitation due to current stimulation (but see also the extended model in Fig. 9). Even with inhibition preceding the excitation, individual inhibitory events were too weak to overcome endbulb-like excitation of $50 \mathrm{nS}$. However, the strong summation of inhibitory conductance during pulse trains eventually interfered with the excitation (Fig. 7Ci). This was, however, only true for the synergistic glycine + GABA conductance (Fig. 7Cii, black trace). The GABAergic component, albeit small in amplitude, increases the total effectiveness of inhibition. This is illustrated in Figure $7 D$ by plotting the conductance of excitatory events and the effective inhibitory conductance during each interaction in a $100 \mathrm{~Hz}$ train combined as coordinates (glycine + GABA: white circles; glycine only: black crosses). The trajectories of EIcoordinates are superimposed on a $2 \mathrm{D}$ plot illustrating the efficacy of inhibition over a wide range of inhibitory and excitatory conductances. Here, hotter colors indicate higher resulting membrane potentials (note that peak $\mathrm{V}_{\mathrm{m}}$ of respective EPSP and AP events is plotted with corresponding color-coded waveforms on the right). These data demonstrate that, for the assumed endbulb-triggered conductance of $50 \mathrm{nS}$, the additional GABAergic component expands the effective inhibitory strength into the range of secure spike suppression.

We next assessed the impact of inhibitory conductance during simulated $100 \mathrm{~Hz}$ neuronal activity in analogy to the experiments shown in Figure 6. For this, a range of initial inhibitory conductances was regarded interacting with a fixed excitatory conductance. As measures of inhibitory efficacy, the fraction of spikes in the train (Fig. $7 E$ ) and the time of spike occurrence after the last inhibitory event were quantified (Fig. $7 F$ ). Figure $7 E$ illustrates the inhibitory conductances necessary to suppress spikes in a 100 $\mathrm{Hz}$ train. The glycinergic component alone abolished spiking for excitation $<42 \mathrm{nS}$ but failed to suppress spiking when excitation was $>57 \mathrm{nS}$. The glycine + GABA inhibition efficiently blocked APs when excitation was $<45 \mathrm{nS}$ and had no effect when $\mathrm{g}_{\text {exc }}$ was $>65 \mathrm{nS}$.

These results strongly corroborate the hypothesis that synergistic glycine-GABA action extends the inhibitory potency to a
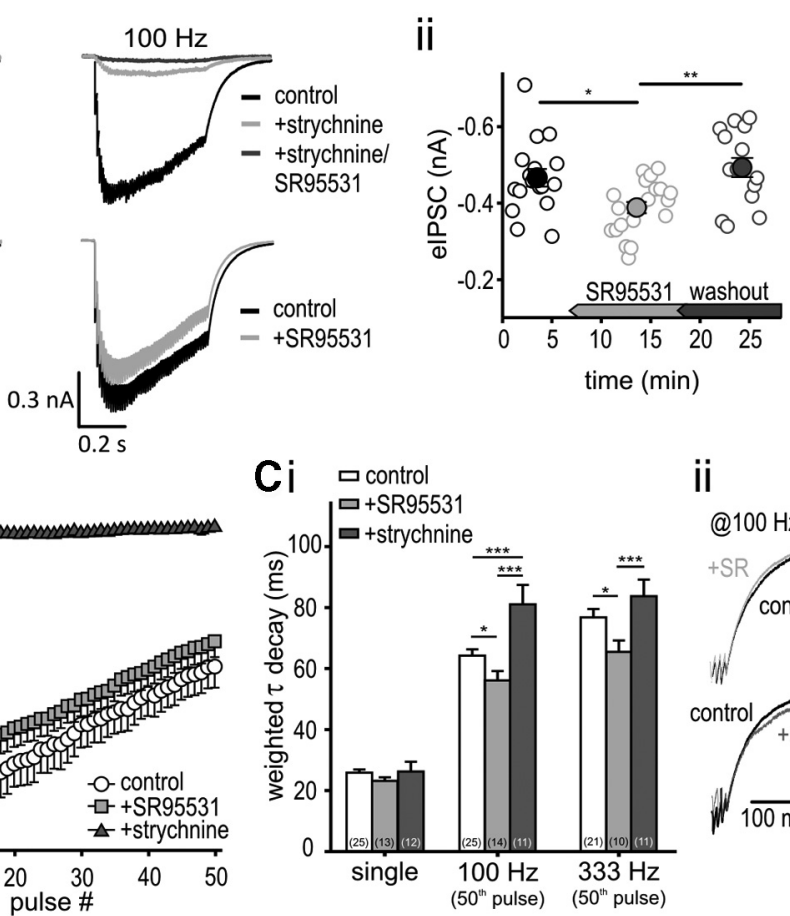

ii

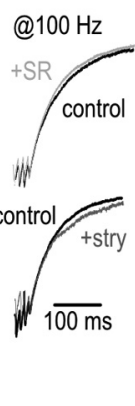

Figure 5. GABA enhances and prolongs the predominantly glycinergic inhibition. Ai, elPSCs (single [left] and $100 \mathrm{~Hz}$ stimulation [right]) are differentially affected by $1 \mu \mathrm{m}$ strychnine and $20 \mu \mathrm{m}$ SR95531 but completely blocked by a combination of both

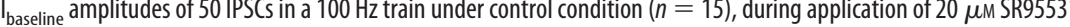
train. Ci, Fast glycinergic and slow GABAergic transmission differentially shape the inhibitory kinetics in an activity-dependent 列 by $\mathrm{GABA}_{\mathrm{A}}$ signaling at higher input frequencies having $\tau_{\mathrm{w}}$ at $333 \mathrm{~Hz}$ similar to isolated GABA current. ${ }^{*} p<0.05$ (two-way ANOVA) ${ }^{* * *} p<0.001$ (two-way ANOVA). Cell numbers are given in parentheses. Cii, Representative traces showing a faster decay of an isolated glycinergic current ( $+S R)$ and slower decay of an isolated $\mathrm{GABA}_{A}$-mediated current (+stry).

higher range of excitatory conductances. Figure $7 F$ shows the duration of inhibitory effect in the model (compare Fig. 6E). In contrast to slice measurements, there was no difference between the sole glycinergic and the glycine-GABA inhibition. In both cases, the effective inhibitory conductance ended too fast to suppress the next event in the train. This indicates that our model is probably not taking into account all aspects of inhibitory synapse dynamics. The proportionally stronger prolongation of GABAergic decay rate, compared with glycinergic decay rate, was not included in the model. This most likely underlies the prolonged effect of inhibition on spike probability in slice recordings.

Together, the in silico data suggest that the slow inhibition found in the in vitro experiments has the potency to effectively suppress endbulb-triggered AP generation, whereby the inhibitory strength and the dynamics are finely tuned through interaction of glycinergic and GABAergic mechanisms.

\section{Slow inhibitory dynamics in vivo}

Excitatory acoustic stimulation at SBC's CF evokes a primary-like response, characterized by a rapid increase in AP spiking followed by a steady-state activity during ongoing stimulation (Blackburn and Sachs, 1989; Typlt et al., 2012). The response to excitatory auditory nerve (AN) fiber input, triggered by a tone burst at CF (20 dB above threshold), is characterized by the initial increase in 
A

current injection $(100 \mathrm{~Hz})$

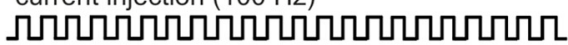
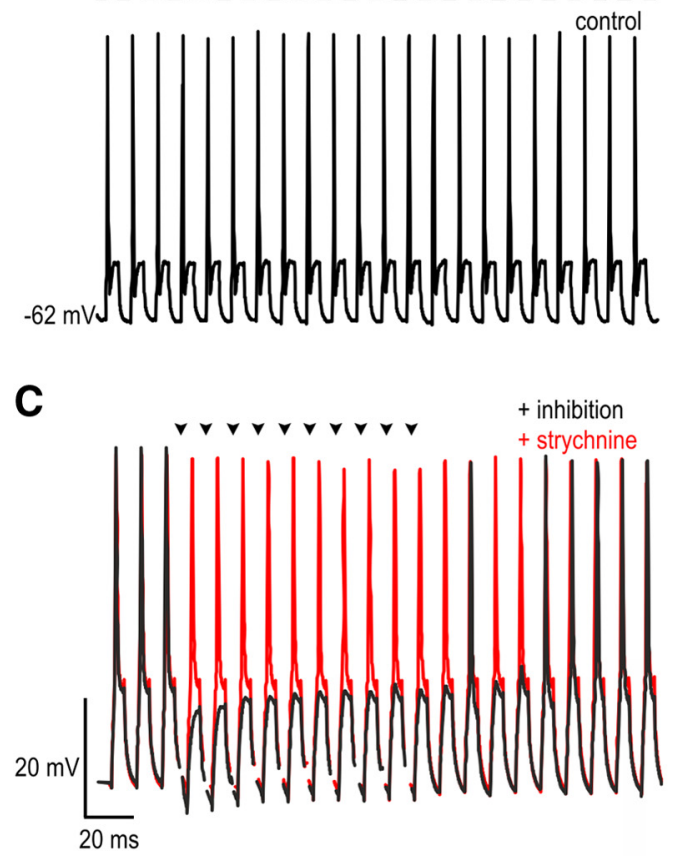

E

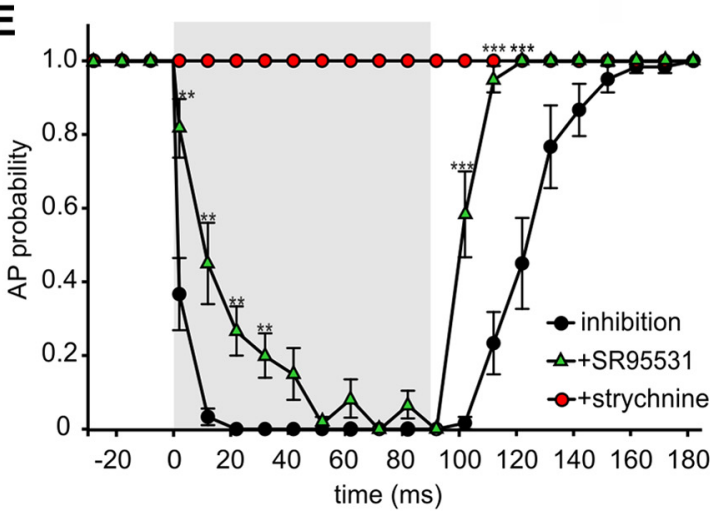

B
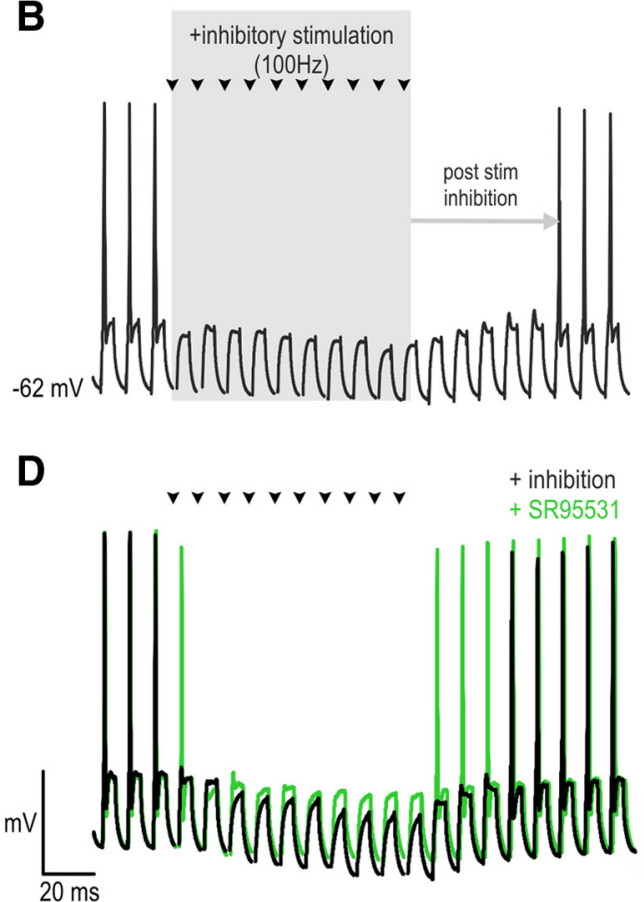

$F$

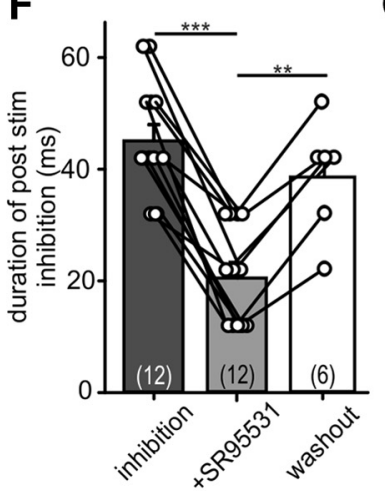

G

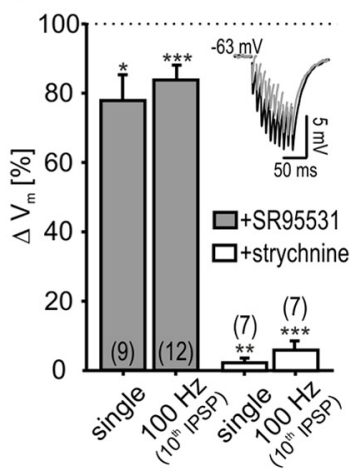

Figure 6. Synergistic action of glycine and GABA increases the efficiency of inhibition. $A$, APs generated by $100 \mathrm{~Hz}$ depolarizing current injections (5 ms) set at minimum amplitude to trigger reliable spiking throughout the stimulus train. $\boldsymbol{B}$, Additional stimulation of inhibitory inputs (10 pulses, $100 \mathrm{~Hz}$, arrowheads within gray window) completely abolished APs during and also for a prolonged period after stimulation. $\boldsymbol{C}, \boldsymbol{D}$, Superfusion of strychnine $(0.5 \mu \mathrm{M}$, red) fully reversed the synaptically evoked AP inhibition. SR95531 (20 $\mu \mathrm{m}$, green) postponed the onset and shortened the inhibitory effect after synaptic stimulation. $\boldsymbol{E}$, Changes of AP probability during synaptic stimulation of inhibition; control condition is full inhibition $(n=12)$, superfusion of $S R 95531$ ( $n=12$ ), or strychnine $(n=5)$. Stimulation was conducted between 0 and $90 \mathrm{~ms}$ (gray background). Note the slow onset and shorter offset of inhibition after the GABA $A_{A}$ receptor blockade (SR95531). $\boldsymbol{F}$, Duration of ongoing AP suppression after stimulation of inhibitory inputs (period of AP inhibition after the gray window in $B, E$ ) with and without $G_{A B A}-R$ contribution. The effect of $S R 95531$ was reversible. Circles represent individual cells; bars represent values ( \pm SEM). Cell numbers are given in parentheses. ${ }^{* *} p<0.01$ (ANOVA). ${ }^{* * *} p<0.001$ (ANOVA). G, Relative contributions of glycine and $G_{A B A_{A}}$ receptors to the total hyperpolarization evoked by synaptic stimulation of inhibitory inputs (10th pulse at $100 \mathrm{~Hz}$ ). Bars represent the remaining hyperpolarization under SR95531 or strychnine relative to corresponding cotransmission control (100\%). ${ }^{*} p<0.05$; ${ }^{* *} p<0.01$; ${ }^{* * *} p<0.001$ (paired $t$ test for each condition vs respective control).

firing rate (onset) and the spike rate reduction at the end of the stimulus (offset) (Fig. 8Aii, gray line; onset: $3.6 \mathrm{~ms}$, offset: 1.8 $\mathrm{ms}$ ). When the tone burst was presented in the unit's inhibitory sideband (Fig. $1 B$ ), the AP rate was reduced, although the excitatory input to the SBC remained constant, as seen from the steady EPSP rate shown as mean for 16 cells (Fig. $8 A i$ ). The time course of AP inhibition in vivo, assessed as the dynamics of the increase in AP failure rate during inhibitory sideband stimulation, showed a slow onset (half-rise time from stimulus onset $=7.3 \mathrm{~ms}, n=16$ ) (Fig. 8Aii, red). Moreover, the failure fraction tapered down during ongoing inhibitory stimulation, being significantly lower at its end (15-30 ms vs $80-95 \mathrm{~ms} ; 0.64 \pm 0.19$ vs $0.58 \pm 0.18, n=16$, $p<0.01$, paired $t$ test). Also, the release from inhibition was remarkably slower than the offset of excitation (Fig. 8Aii; decay time constant computed from fitting the average trace for 16 units: $\tau_{\text {inhibition }}=9.8 \mathrm{~ms}$ [95\% confidence interval: $5.9,14.1 \mathrm{~ms}$ ], $\tau_{\text {excitation }}=1.4$ [95\% confidence interval: $0.7,2.0 \mathrm{~ms}$ ], black and gray, respectively). One conspicuous effect of inhibition, consistent across in vivo and slice experiments, was the change of the EPSP slope and prolongation of the EPSP-to-AP transition time (Fig. 2). Notably, the prolongation of the EPSP-to-AP delay was most prominent after the onset of inhibitory stimulation, reaching maximal delay values within initial $30 \mathrm{~ms}$. Although the delay remained prolonged during ongoing inhibitory stimulation (Fig. 8Aiii; average delay for $150-230 \mathrm{~ms}$ spontaneous activity = $0.23 \pm 0.02 \mathrm{~ms}$; average delay during $10-90 \mathrm{~ms}$ of inhibitory stimulation $=0.25 \pm 0.02 \mathrm{~ms}, n=16, p<0.001$, paired $t$ test), this effect became progressively weaker with time (EPSP-to-AP 
A

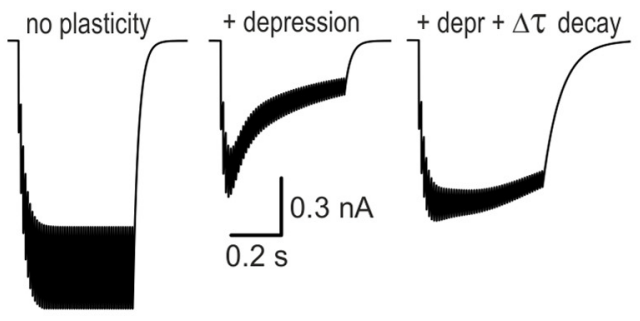

B

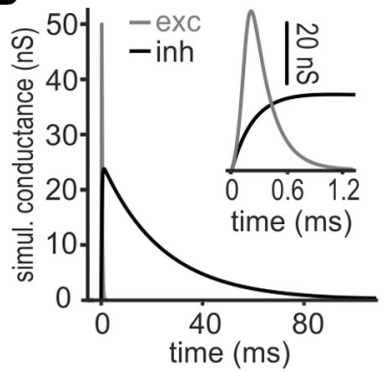

$\mathrm{C}_{\mathrm{i}}$
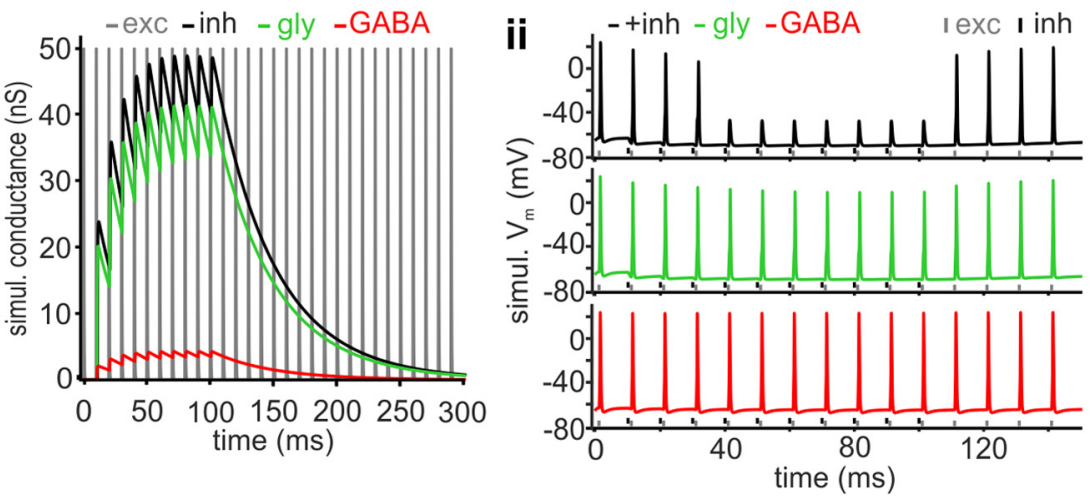

D

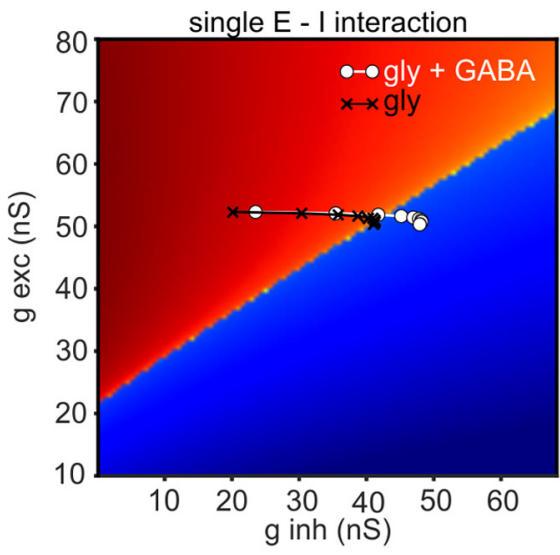

E

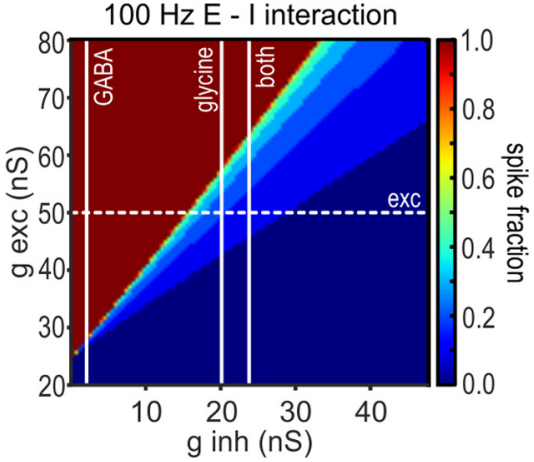

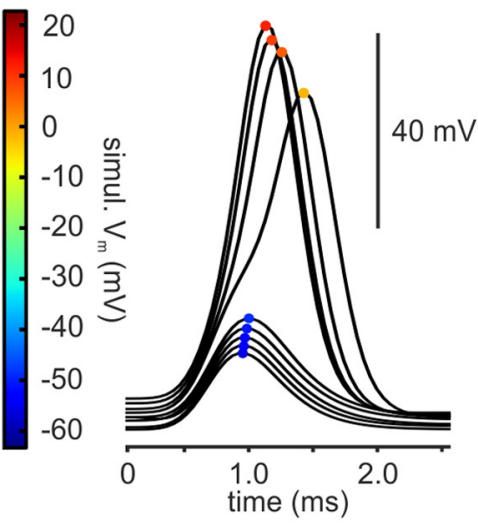

$\mathbf{F}$

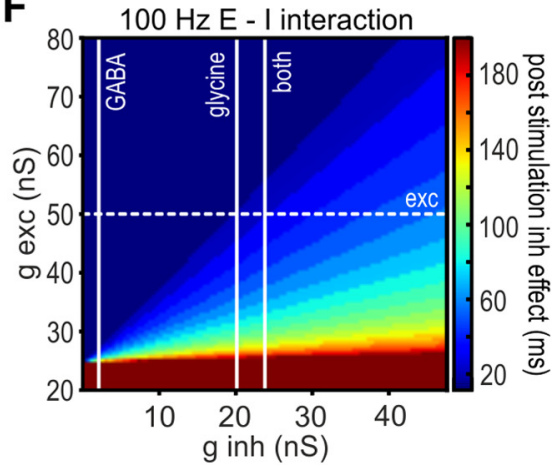

Figure 7. In silico estimation of the inhibitory synaptic strength. $\boldsymbol{A}$, Simulated membrane currents of the SBC model during 100 $\mathrm{Hz}$ synaptic activation of the inhibitory transmission. Traces were simulated with (left) a constant $g_{\text {inh }}$ (no plasticity), (middle) $g_{\text {inh }}$ considering the change through $\mathrm{I}_{\text {peak }}$ depression as measured in slice recordings, and (right) the full model additionally considering the assessed weighted decay time constant prolongation. The last most reliably describes the eIPSCs from slice recordings. $\boldsymbol{B}$ Waveform comparison of inhibitory (black) and excitatory (gray) conductance templates. Inset, The rapid kinetic of the excitatory conductance is shown enlarged. $C$, Inhibitory and excitatory conductances interacting at $100 \mathrm{~Hz}$ stimulation in the SBC model. The former is leading by $1 \mathrm{~ms}$. Glycinergic and GABAergic components are modeled as additive conductances (compare Fig. 5). Ci, Buildup of effective GABAergic (red), glycinergic (green), and combined (black) inhibitory conductances (full model) during a 100 $\mathrm{Hz}$ train of excitatory pulses (gray vertical lines) with 10 inhibitory pulses embedded. Cii, Simulated membrane potential for interactions of inhibitory and excitatory conductances. Small vertical lines below traces indicate inhibitory (black) and excitatory (gray) spike times. Note the much higher inhibitory potency of combined conductance ( + inh, black) compared with the sole

delay during 15-30 ms of inhibitory stimulation $=0.25 \pm 0.02 \mathrm{~ms}$; during $80-95$ $\mathrm{ms}=0.24 \pm 0.02 \mathrm{~ms} ; n=16, p<0.01$, paired $t$ test). After the release from inhibition, the delay decreased to initial values with a time constant of $\tau=14.7 \mathrm{~ms}$ ( $95 \%$ confidence interval: $12.1,17.4 \mathrm{~ms}$ ), calculated from fitting the average trace from 16 units.

Finally, in silico experiments were used to explore whether the EPSP-to-AP delay prolongation could be reproduced with inhibitory parameters assessed from slice experiments. Indeed, during excitationinhibition interaction, the AP peak delay strongly depended on the conductance strength revealing that AP initiation close to threshold (i.e., excitation at just marginally suprathreshold values) caused a later occurring peak (Fig. $8 B$ ). The dynamics of EPSP-to-AP prolongation showed a time course that was approximately comparable with in vivo recordings (Fig. 8C, compare Fig. 8Aiii). Increased delay values were reached within the first few events, but after reaching a maximum, the delay was progressively reduced depending on inhibitory conductance strength. However, small variations in the balance between excitatory and inhibitory conductance can have tremendous impact on the EPSPto-AP delay in the model (Fig. $8 B$ ). Thus, in this context only a qualitative comparison can be made between the in vivo and in silico results. These data imply that the dynamic efficacy of inhibition, as observed in vivo, crucially depends on the

glycinergic (green) or GABAergic (red) conductance. $\boldsymbol{D}$, Single interaction of excitatory and inhibitory synaptic conductances was simulated to estimate the inhibitory power $\left(g_{\text {inh }}=\right.$ $0-68.3 \mathrm{nS}, \mathrm{g}_{\text {exc }}=10-80 \mathrm{nS}$, inhibition leading by $1 \mathrm{~ms}, n=$ $10^{4}$ interaction combinations). Map color represents peak simulated membrane potential of the SBC model (left). The effective inhibitory conductance of glycinergic (initial $\mathrm{g}=$ $20.1 \mathrm{nS}$, black crosses) or combined (initial gly + GABA $\mathrm{g}=$ $23.8 \mathrm{nS}$, white dots) inhibition in a $100 \mathrm{~Hz}$ train (see (i) is superimposed onto the map as a trajectory of effective conductance at given spike time. Addition of GABA causes a shift of membrane potential to subthreshold $V_{m}$ values. Excitatory conductance values were slightly shifted to avoid overlapping of symbols. Color-coded $V_{m}$ values in the plot on the left indicate the peak $V_{m}$ of the waveforms shown on the right. $E, F$, The $100 \mathrm{~Hz}$-l interaction (see Cii) was simulated for a range of inhibitory (0.1-47.6 nS, full model) and excitatory $(20-80$ $\mathrm{nS}$, fixed) initial conductances ( $n=10^{4}$ interactions). $\boldsymbol{E}$, Fraction of spikes (number of APs divided by number of EPSPS) during the $100 \mathrm{~Hz}$ E-l interaction. $\boldsymbol{F}$, Poststimulation inhibitory effect: white vertical lines indicate initial conductance of GABAergic, glycinergic, or combined inhibition; dashed horizontal line indicates excitatory conductance of $50 \mathrm{nS}$ used in most simulations. 

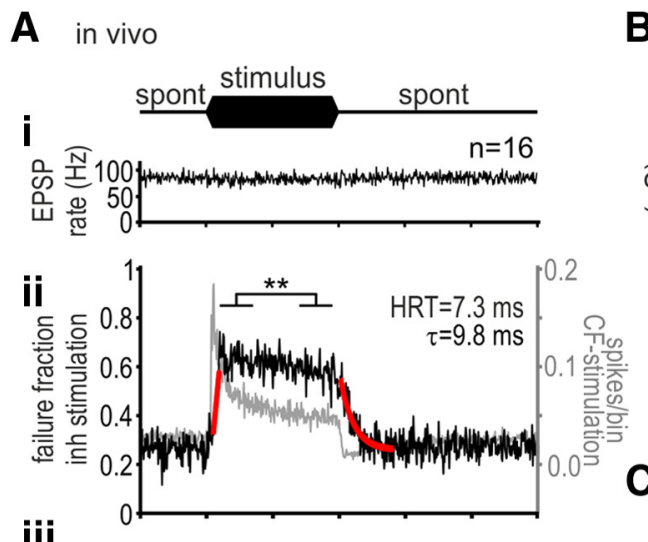

B model
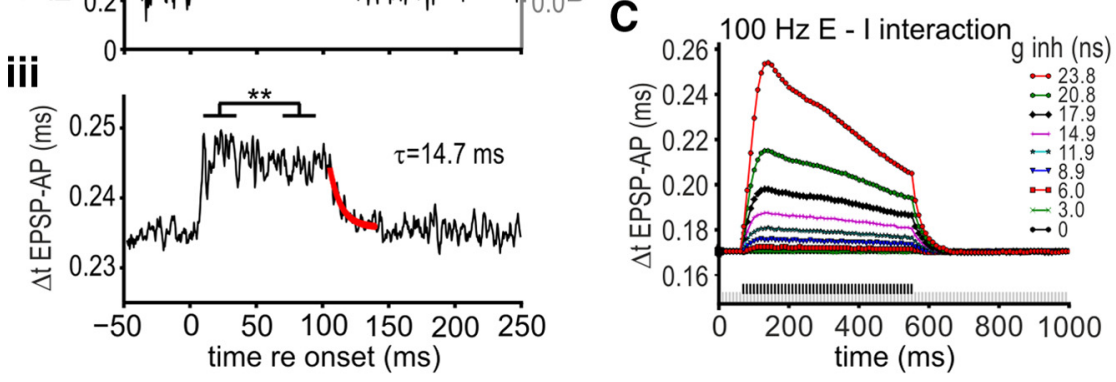

Figure 8. Time course of inhibition in vivo and in the model. $\boldsymbol{A}$, Average data for 16 units recorded in vivo. Ai, Acoustic stimulation (black bar) within the unit's inhibitory sideband (median $\mathrm{F}_{\text {inh }}=4.8 \mathrm{kHz}, 4.2 \leq \mathrm{F}_{\text {inh }} \leq 8 \mathrm{kHz}$, mean $\pm \mathrm{SD} \mathrm{SPL}=$ $63.4 \pm 20.9 \mathrm{~dB}, n=16$ ) did not change the AN input rate (EPSP rate) (mean rate $=86.8 \pm 39.4 \mathrm{~Hz}, 60.74 \leq \mathrm{Hz} \leq 105.5$ ). Aii, Inhibitory stimulation increased the failure fraction with a slow onset dynamic (left ordinate, black line; average for baseline $150-230$ ms vs average for $10-90$ ms inhibitory stimulation: $0.27 \pm 0.13$ vs $0.61 \pm 0.19, p<0.001$, paired $t$ test, $n=16$; red line; mean half-rise time $=7.3 \mathrm{~ms}$ ). In the course of stimulation, the failure fraction tapered down (periods $15-30 \mathrm{~ms}$ and $80-95$ ms were averaged and compared, ${ }^{* *} p<0.01$, paired $t$ test). The failure fraction slowly decreased further after the end of stimulation (red line; mean $\tau$ decay $=9.8 \mathrm{~ms}$ ). The PSTH for (F stimulation is shown for comparison (right ordinate, gray line; median $\mathrm{CF}=2 \mathrm{kHz}, 0.9 \leq \mathrm{CF} \leq 4.6 \mathrm{kHz}$, SPL $=55.6 \pm 24.2 \mathrm{~dB}, n=16)$. The discharge rate shows the typical phasic-tonic response pattern with fast onset/offset. Aiii, APs evoked during inhibitory stimulation show a dynamic prolongation of EPSP-to-AP transition, which was most prominent at stimulation onset (comparison as in Aii: spontaneous vs inhibitory stimulation $p<0.001$; EPSP-to-AP delay early stimulation vs EPSP-to-AP delay late stimulation $p=0.006$, paired $t$ test). Note the similar time courses of the EPSP-to-AP transition delay and the failure fraction. $\boldsymbol{B}$, Impact of E-I interaction on the transmission delay measured as the interval between the presynaptic spike time and postsynaptic AP peak in the SBC model. Single interactions of excitatory and inhibitory synaptic events were simulated for a range of inhibitory and excitatory conductances $\left(\mathrm{g}_{\mathrm{inh}}=0-68.3 \mathrm{nS}, \mathrm{g}_{\mathrm{exc}}=10-80\right.$ $\mathrm{nS}$, inhibition leading by $1 \mathrm{~ms}, n=10^{4}$ interaction combinations). Color represents transmission delay from short (blue) to long (red). White area represents subthreshold EPSP (i.e., no APs elicited). C, Gradual increase in EPSP-to-AP delay, caused by summation of the effective inhibitory conductance during simulated $100 \mathrm{~Hz}$ stimulation in the SBC model. Vertical lines below the traces indicate inhibitory (black) and excitatory (gray) spike times. Whereas the excitatory synaptic conductance was fixed at $50 \mathrm{nS}$, inhibitory conductances were tested in the range $0-23.8 \mathrm{nS}$ (full model). Depending on initial inhibitory synaptic conductance, a plateau of the transmission delay is reached within $4-6 \mathrm{E}-\mathrm{I}$ interactions, causing a net EPSP-to-AP prolongation of $<80 \mu \mathrm{s}$.

inhibitory conductance profile characterized by the current depression and tau prolongation (Fig. 7A). Modeling the inhibitory conductance without $\tau$ plasticity and/or depression yields a time course of delay prolongation different from the in vivo data (data not shown).

To explore the properties of the inhibition during in vivo-like spontaneous and sound-evoked activities, the inhibitory conductance profiles measured in slice experiments were used. To this end, AN spike trains (2s) were generated and implemented to drive excitatory as well as inhibitory synaptic mechanisms. The inhibition was trailing the excitation by $1 \mathrm{~ms}$, assuming the engagement of an additional synapse activated by AN fibers (Wickesberg and Oertel, 1990; Xie and Manis, 2013; Campagnola and Manis, 2014). Spontaneous AN events (30 \pm 5 spikes/s) reliably caused action potentials in the SBC although the inhibitory conductance showed activity-dependent buildup (Fig. 9Ai-Ci, AiiCii). Modeling of stochastic and dynamic endbulb conductances revealed failures occurring during spontaneous activity. Thus, in combination with variable excitatory conductances, tonic inhibition caused some failures during spontaneous activity, as shown by the analysis of 100 repetitions (Fig. 9Aiii-Ciii). However, failure incidence strongly increased during the response to simulated sound bursts $(201 \pm 37$ spikes/s) (red, Fig. 9Aii-Cii). The quantification of spike probability during simulated acoustic responses for all three conditions yielded different results: in the fixed endbulb condition (black line), the probability dropped from $p=0.95 \pm 0.11$ to $p=0.23 \pm 0.22$, in the stochastic endbulb condition (orange line) from $p=$ $0.88 \pm 0.08$ to $p=0.4 \pm 0.17$, and in the dynamic endbulb condition (blue line) from $p=0.74 \pm 0.13$ to $p=0.1 \pm 0.21$ (Fig. 9D). Notably, in the dynamic endbulb condition, the spike probability dropped to zero in the sustained part of the simulated acoustic responses due to strong depression at high input rates. In addition to increased refractoriness related to short interspike intervals (data not shown), the reduction in spike probability was mainly caused by a strong increase in tonically active inhibitory conductance from $21.5 \pm 0.9 \mathrm{nS}$ to $43.8 \pm 7.8 \mathrm{nS}$ (Fig. $9 G$ ). The spike probability measured in vivo changed from $p=0.73$ to $p=0.36$ during acoustic stimulation in the inhibitory sideband and the inhibition offset had the time constant of 9.8 ms (Fig. 8Aii). Compared with these data, the offset of inhibition computed by our models was in the same range being 5 $\mathrm{ms}$ for the fixed and $20 \mathrm{~ms}$ for the stochastic excitatory conductance (measured as the time constant of the monoexponential fit to the spike probability traces after the acoustic stimulation; Fig. 9D). Recovery from inhibition was much slower with dynamically depressing excitation.

The tonic inhibition also caused an increase in AP delay of successful events, quantified as the interval between the peaks of the EPSP and AP waveform components. This effect was most pronounced for the fixed endbulb condition (Fig. 9E, black line; EPSP-to-AP delay spontaneous $=0.20 \pm 0.01 \mathrm{~ms}$; stimulation $=0.24 \pm 0.03 \mathrm{~ms}$; maximum $=0.31 \mathrm{~ms}$ ), and less strong for the stochastic endbulb condition (orange line; EPSP-to-AP delay spontaneous $=0.20 \pm 0.01 \mathrm{~ms}$; stimulation $=0.22 \pm 0.02 \mathrm{~ms}$; maximum $=0.25 \mathrm{~ms}$ ). In the dynamic endbulb condition, EPSPto-AP delay initially increased up to $0.26 \mathrm{~ms}$ but could not be determined throughout the ongoing simulated acoustic response, as only few successful events occurred. Nevertheless, the EPSP-to-AP delay was still increased to $0.26 \mathrm{~ms}$ at $34 \mathrm{~ms}$ after stimulus and returned to normal only after $>50 \mathrm{~ms}$. On the other hand, the effect on the delay prolongation decayed with a $\tau=15$ $\mathrm{ms}$ for fixed and $\tau=48 \mathrm{~ms}$ for the stochastic synapse model, which is comparable to $\tau=14.7 \mathrm{~ms}$ measured in vivo (Fig. 8Aiii).

The time course of the mean endbulb EPSG underlying the dynamic condition showed a tonic depression to $81.5 \%$ (61.1 \pm $2.8 \mathrm{nS}$; Fig. 9F) during the spontaneous activity. Depression further increased during simulated sound evoked activity resulting in $43.5 \%$ EPSG of the initial value $(32.6 \pm 11.1 \mathrm{nS})$. At the end of 

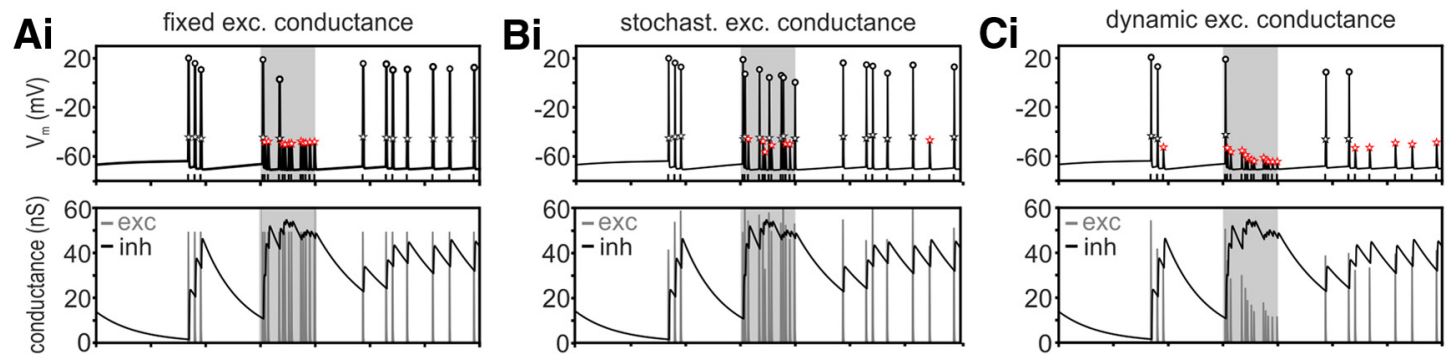

\section{Aii}

Bii

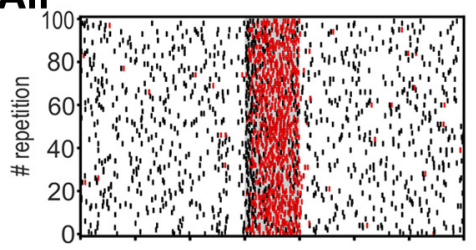

100
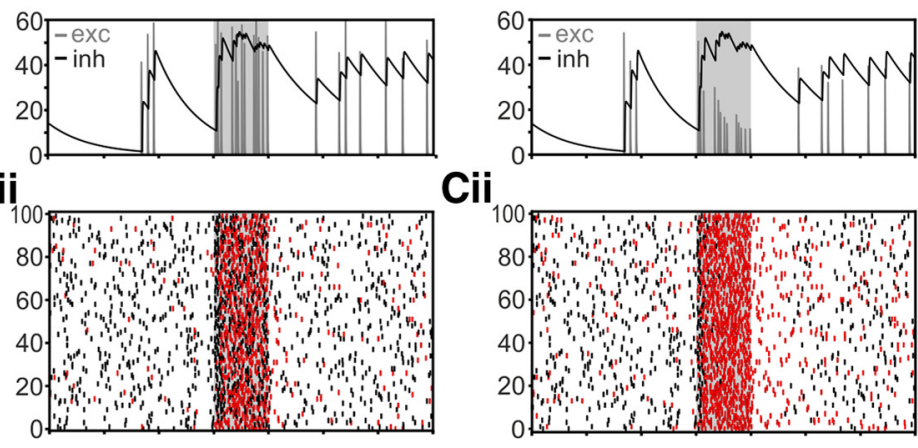

Cii
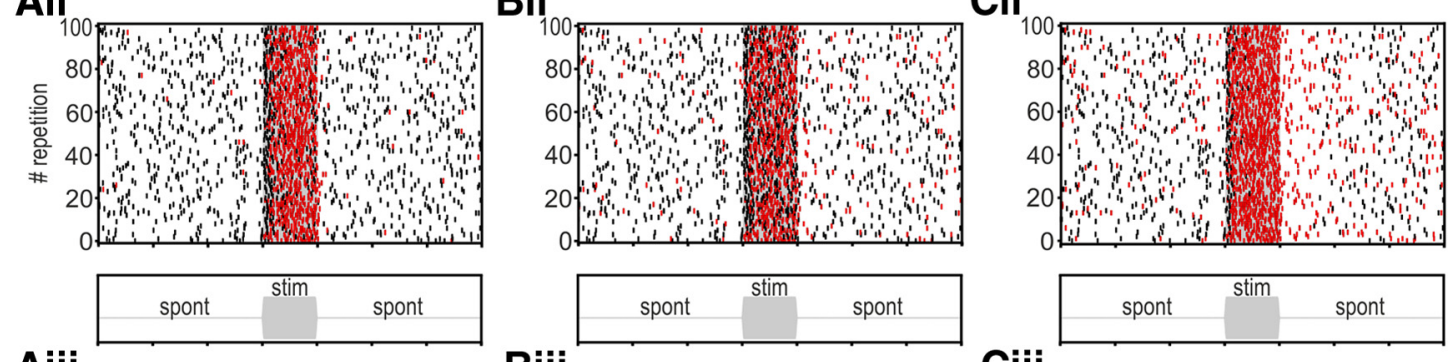

Aiii
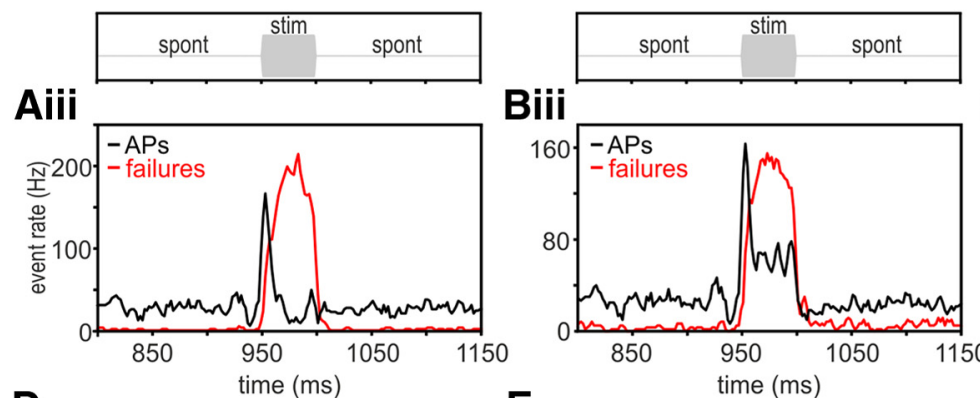

Biii

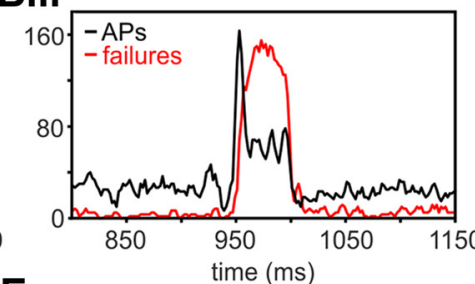

\section{Ciii}
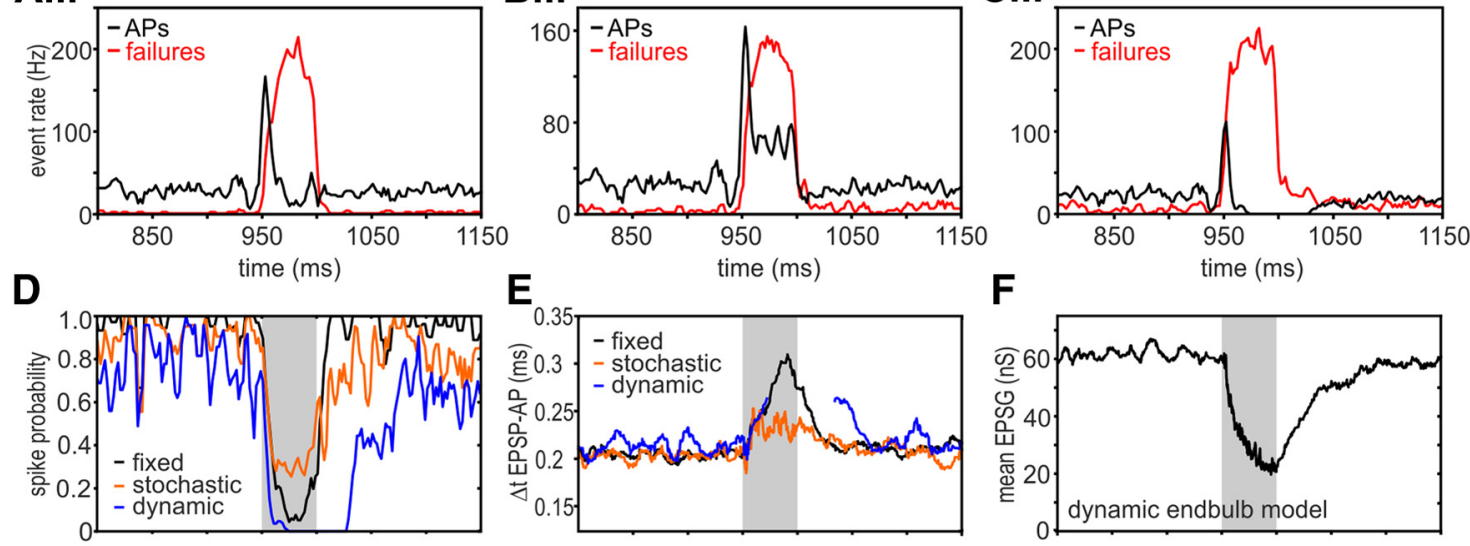

$F$
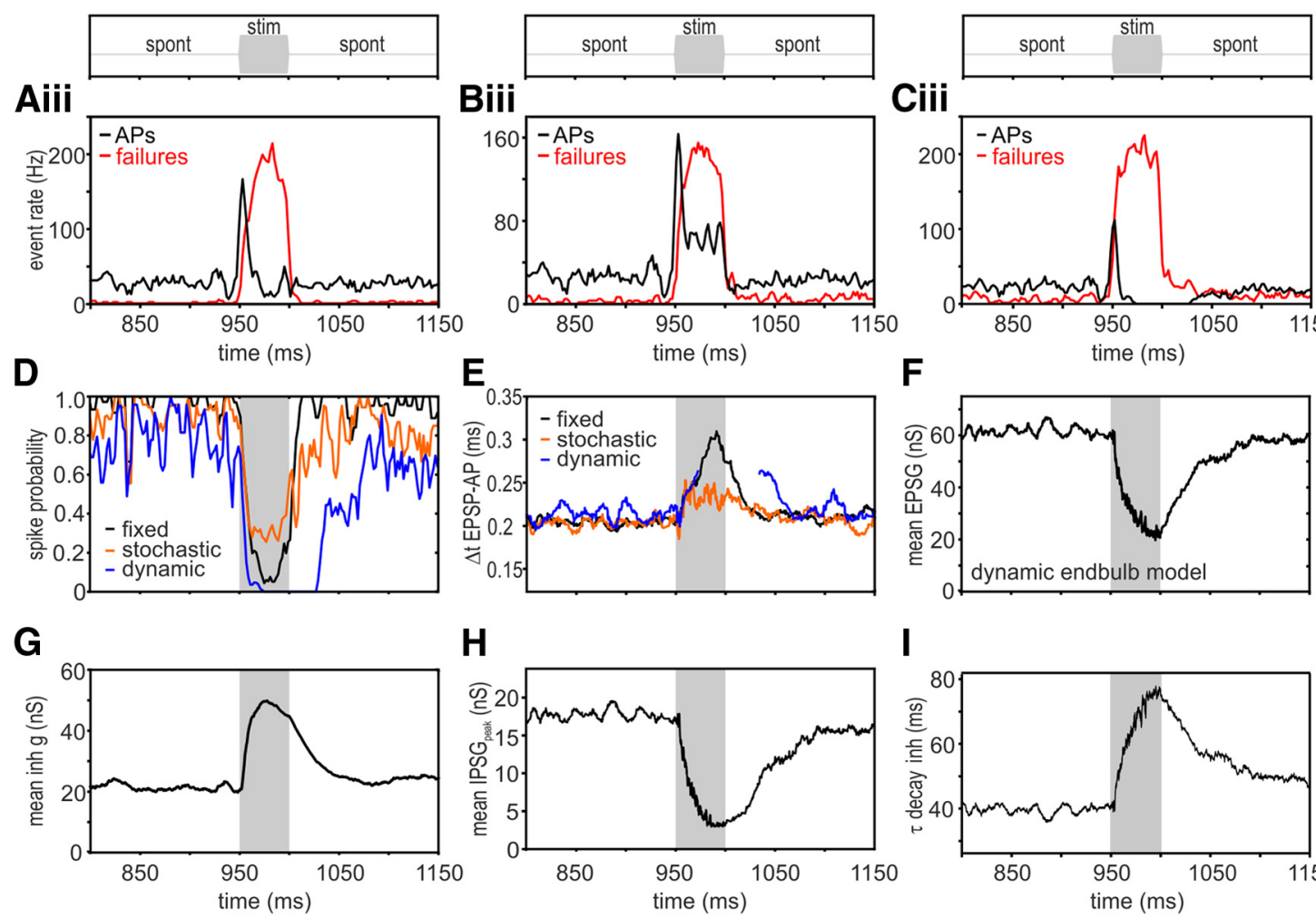

H

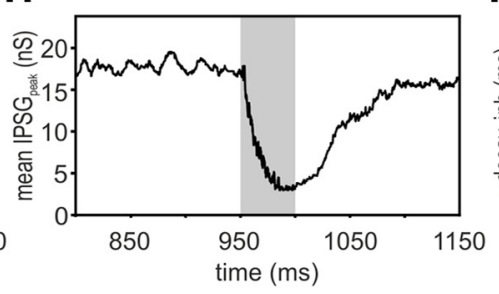

I

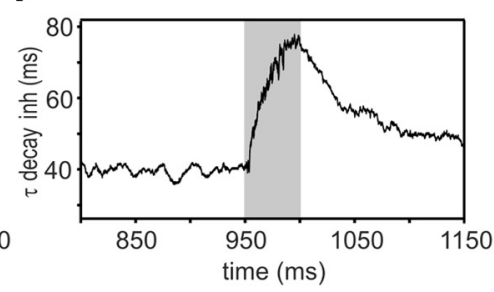

Figure 9. Simulation of excitation-inhibition interaction driven by AN-like spike trains for $2000 \mathrm{~ms}$. Graphs represent the time span $800-1150$ ms with an embedded acoustic-like stimulus presented from 950 to $1000 \mathrm{~ms}$ (Ai-Cii, D-I, gray area). Ai-Aiii, Synapse model with fixed excitatory conductance. Bi-Biii, Model with stochastically variable excitatory conductance. Ci-Ciii, Model implementing dynamic excitatory synapse depression. $A \mathbf{A}, \mathbf{B i}$, Ci, Simulated SBC membrane potential in response to AN spike train yields time points of EPSP (stars) and AP (dots) Components. Short vertical bars below the voltage trace represent input spike times; red stars represent corresponding failures produced during inhibition; white stars represent suprathreshold EPSPs resulting in APs. The inhibitory conductance was simulated with short-term plasticity and increase of $\tau$ decay (full model, black line in bottom) in response to auditory-nerve like spike trains. Note the differences in the excitatory conductances (gray line) resulting from respective models. Inhibitory and excitatory synaptic mechanisms are driven by identical spike trains with inhibition trailing by $1 \mathrm{~ms}$. During spontaneous activity, a certain level of inhibitory conductance is achieved through summation (mean active $\mathrm{g}_{\mathrm{inh}}=18 \pm 10 \mathrm{nS}$ ). Acoustic-like stimulation caused a graded conductance increase (mean active $\mathrm{g}_{\mathrm{inh}}=43 \pm 10 \mathrm{nS}$ ). Aii, Bii, Cii, Rasterplot of $100 \mathrm{AN}$ spike train repetitions shown as in $\mathbf{A i}$, Bi, and $\mathbf{C i}$ for the three synaptic models. Black bars represent postsynaptic APs; red bars represent spike failures. Aiii, Biii, Ciii, Average rate of successful events (APs, black line) and failures (red line) in 1 ms time bins. D-I, Different time-variant parameters averaged across 100 stimulus repetitions in the three $S B C$ models. $D$, Comparison of the spike probability, calculated as fraction of successful events per $1 \mathrm{~ms}$ revealed the most prominent inhibition in the dynamic model. $E$, EPSP-to-AP transition time gradually increases depending on summation of inhibitory conductance. In the dynamic model, the computation of the EPSP-to-AP delay was only possible at the onset of inhibition because the events were lacking thereafter. $\boldsymbol{F}$, Average active excitatory conductance for the dynamic endbulb model. $\mathbf{G}$, Average tonically active inhibitory conductance before the stimulation $\mathrm{g}_{\text {inh }}=21.5 \pm 0.9 \mathrm{nS}$, during $\mathrm{g}_{\text {inh }}=43.8 \pm 7.8 \mathrm{nS}$, and after the stimulation $\mathrm{g}_{\text {inh }}=20.4 \pm 0.9 \mathrm{nS}$. $\boldsymbol{H}$, The phasic inhibitory conductance shows prominent depression during ongoing activity. I, Acoustic-like stimulation prolongs the mean effective $\tau$ decay of inhibitory synaptic conductance.

the simulated sound-evoked response, EPSG was as low as $26.3 \%$ (19.7 nS). Consistent with the slice data, the activity-evoked inhibition showed a dynamic change of the phasic amplitude of individual events (Fig. $9 \mathrm{H}$; spontaneous $=18.1 \pm 1.3 \mathrm{nS}$; stimulation $=6.9 \pm 4.3 \mathrm{nS}$ ) and in $\tau$ decay (Fig. 9I; spontaneous $=$
$40.3 \pm 6.5 \mathrm{~ms} ;$ stimulation $=64.1 \pm 13.4 \mathrm{~ms})$. After acoustic-like stimulation at the average rate of $201 \pm 37$ spikes/s, the prolonged $\tau$ decay returned back to initial value with a time constant of $99 \mathrm{~ms}$. Very similar decay rate was measured in slice experiments after the $200 \mathrm{~Hz}$ stimulation (weighted $\tau$ decay of $\sim 80 \mathrm{~ms}$; Fig. $3 F$ ). 
In summary, because of the rate-dependent dynamics of the inhibitory input, its efficacy against a fixed excitatory conductance gradually increased during the initial part of the stimulus response, reached a maximum, and thereafter declined despite the ongoing presentation of the inhibitory stimulus. Against the stochastically variant excitatory conductance, the overall potency of the inhibition was on average lower but still efficient in the ongoing part of the simulated stimulus response. Counteracting the dynamically depressing excitatory conductance, inhibition was overwhelmingly efficient, completely silencing all spiking activity in the model SBC for $>50 \mathrm{~ms}$. Together, the data obtained by using the fixed and stochastic endbulb model are compatible with the time course of inhibitory action measured in vivo (Fig. 8 ). Hence, the modeling results demonstrate that synergistic glycine/GABAergic transmission yields inhibitory input that effectively constrains AP generation at input rates characteristic for acoustically evoked activity.

\section{Discussion}

Synaptic inhibition in auditory brainstem circuits of mammals is mostly mediated by glycine, but few auditory synapses use both GABA and glycine beyond the early postnatal development (Balakrishnan and Trussell, 2008; Balakrishnan et al., 2009; Apostolides and Trussell, 2013). To date, it remained elusive why both glycine- $\mathrm{R}$ and $\mathrm{GABA}_{\mathrm{A}}-\mathrm{R}$ are engaged with inhibition of SBCs and what is the inherent advantage of such a twotransmitter inhibitory mechanism. We addressed this question using the endbulb of Held-SBC synapse, which allows for an in vivo assessment of input-output function based on the analysis of systemic, acoustically evoked activity. This model synapse enables characterization of a combined glycine-GABA inhibition in slice experiments and further in vivo evaluation of its impact. We combined both approaches with in silico modeling to demonstrate that the acoustically evoked inhibition enables only strong or coincident excitatory inputs to generate APs. Hence, the slow glycine-GABA inhibition acts as a dynamic high-pass filter. The time course of acoustically evoked AP inhibition in vivo matches the inhibitory conductance profile characterized by a transient summation followed by depression. Comparable inhibitory action was observed in the models assuming fixed or stochastically changing excitatory conductances, whereas modeled inhibitory conductance was apparently too potent when interacting with dynamically depressing excitation. The dual glycine-GABA synaptic transmission endows each transmitter with a distinct function: whereas the glycinergic component dominates the inhibitory conductance of evoked and spontaneous IPSCs, the GABAergic fraction extends the offset of inhibition in an activitydependent manner. By increasing the inhibitory strength and prolonging the decay time, signaling via $G_{A B A}-R$ effectively increases the capacity of inhibition to counteract the endbulb of Held excitation.

\section{Sole glycinergic versus synergistic glycine-GABA inhibition}

The inhibitory inputs of noncochlear origin (Smith and Rhode, 1989; Benson and Potashner, 1990; Saint Marie et al., 1991; Wenthold, 1991; Oertel and Wickesberg, 1993; Ostapoff et al., 1997; Arnott et al., 2004; Campagnola and Manis, 2014) terminate on SBCs in three classes of synapses: glycinergic, GABAergic, and synapses containing both (Kolston et al., 1992; Juiz et al., 1996; Mahendrasingam et al., 2004). The postnatal structural development of respective inputs spans the period of early auditory experience, reaching adult-like configuration of terminals on SBCs P21 (Luján et al., 2008). These results are validated by the demonstration of glycine- $\mathrm{R}$ (Wenthold et al., 1988) and $\mathrm{GABA}_{\mathrm{A}}-\mathrm{R}$ (Campos et al., 2001) on SBCs, as well as the respective uptake transporters in presynaptic terminals (Mahendrasingam et al., 2000). Our data demonstrate that spontaneously occurring (sIPSCs) and events induced by synaptic stimulation (eIPSCs) consisted of both glycinergic and GABAergic components. Although the used experimental protocols enabled us to quantify the physiological impact of the glycine-GABA transmission, we cannot draw a conclusion about the possible corelease of both transmitters from the same vesicle as shown for the spinal and brainstem motoneurons (Jonas et al., 1998; Russier et al., 2002). As indicated above, such an assumption seems plausible, but measurements of miniature IPSCs are necessary to verify this hypothesis.

Across inputs on SBCs, the GABA content in the presynaptic terminals is apparently rather variable, contrasting with the larger and more constant synaptic amount of glycine (Mahendrasingam et al., 2004). Accordingly, the inhibitory strength of a sole $\mathrm{GABA}_{\mathrm{A}}$ signaling was not sufficient to interfere with spike activity per se, as indicated by our slice and modeling data. Still, the GABA contribution to the inhibition cannot be considered a minor one because the impact of the GABAergic fraction can account for up to $\sim 12 \%$ of the total inhibitory conductance during ongoing activity. The activity-dependent depression of glycinergic currents is attributable to the relative increase in GABA component $\left(\mathrm{I}_{\text {peak }}\right.$; compare Fig. 5), which progressively prolongs IPSC kinetics with increasing activity.

Our data from gerbils and results from mice (Xie and Manis, 2013) consistently show slow kinetics of inhibitory currents in SBCs. This seems, prima facie, surprising given the role of SBCs in the submillisecond processing of the temporal information of low-frequency sounds, which is then binaurally integrated by the coincidence detector neurons of the MSO (Smith et al., 1993; Grothe, 2000). The question arises: how can acoustically evoked inhibition, which is orders of magnitude slower than acoustically triggered excitation, contribute to the retention (or even improvement) of temporal resolution? Particularly at higher input frequencies, inhibition is remarkably prolonged by GABA. Yet, the glycinergic IPSCs are also summating due to decay time constants lasting tens of milliseconds. Possible mechanisms for inhibitory current summation are the change to asynchronous transmitter release at high frequencies and/or transmitter pooling due to poor clearance from the synaptic cleft (Lu and Trussell, 2000; Balakrishnan et al., 2009). Hence, depending on the activity, SBC can be controlled by a tonic inhibition arising through current summation (present study and Xie and Manis, 2013), as also shown for DCN granular cells (Balakrishnan and Trussell, 2008). As we presently found no correlation between the amplitudes and the rise times of IPSCs, the longer decay times and larger amplitudes of evoked versus spontaneous events might point to transmitter rebinding and multivesicular release. The fast glycinergic IPSCs in AVCN stellate cells, in MSO, and MNTB neurons, enable phasic inhibition (Awatramani et al., 2004; Magnusson et al., 2005; Chirila et al., 2007; Couchman et al., 2010; Xie and Manis, 2013). Contrary to this, the temporal fidelity in SBC spiking is controlled by a synergistic and rather slow glycineGABA transmission through filtering out the weak, or poorly timed, excitatory inputs.

\section{Contribution of inhibition to auditory processing}

Biophysically, SBCs are characterized by a fast membrane time constant, low input resistance, and nonlinearity of voltage-gated conductances. These properties control the phasic AP responses 
to sharply rising, large EPSPs (Rothman and Manis, 2003; McGinley and Oertel, 2006; Cao et al., 2007). During spontaneous activity in vivo, postsynaptic AP failures occur with an incidence of up to $\sim 20 \%$ probably caused by stochastic fluctuations in excitatory synaptic strength (Englitz et al., 2009; Kuenzel et al., 2011). Our data support this assumption by demonstrating that AP failures are associated with smaller EPSPs, despite constant presynaptic spike amplitudes (Fig. 1). Leaving the excitatory input rate unchanged, the acoustic stimulation within the inhibitory sideband can increase the failure fraction up to $\sim 65 \%$. In such cases, the steepness of the EPSP slope was reduced, supposedly below the integration time window required for AP generation (McGinley and Oertel, 2006). Hence, the dynamic adjustment of hyperpolarizing inhibitory strength mediated by glycine and GABA, as shown by our data, is likely to tune the fidelity of the endbulb of Held synapse to fast rising and large EPSPs.

The spiking activity of SBCs can be synchronized to a particular sine wave phase of a low-frequency tone burst (phasecoupling). Surprisingly, the precision of phase-coupling is improved compared with the AN input (Joris et al., 1994; Paolini et al., 2001; Joris and Smith, 2008). Two mechanisms possibly underlie this improvement: (1) jitter reduction through coincidence detection of convergent inputs (Kuhlmann et al., 2002; Xu-Friedman and Regehr, 2005); and (2) synaptic inhibition mediated by glycine and GABA. Iontophoretic administration of glycine/ $\mathrm{GABA}_{\mathrm{A}}-\mathrm{R}$ antagonists during in vivo recordings and acoustic stimulation at units CFs deteriorated phase-coupling and increased the firing rates at higher stimulus intensities (Dehmel et al., 2010). The latter is probably due to largely overlapping excitatory and inhibitory response areas (on-CF inhibition) (Winter and Palmer, 1990; Kopp-Scheinpflug et al., 2002; Kuenzel et al., 2011). According to our results, the activation of inhibition at higher sound pressure levels might induce larger inhibitory current summation (tonic inhibition due to higher firing rate or recruitment of inputs), leading to both nonmonotonic rate-level function and tightening of phase-coupling (Dehmel et al., 2010). As the sound-driven responses may cause variations in the EPSP slope steepness, we cannot estimate the potency of inhibition at $\mathrm{CF}$, but the overall output would again depend on the actual excitatory conductance determined by the amount of depression, which correlates the input frequency and synchrony of excitatory inputs. In this respect, it is necessary to point out that the observed reduction in APs is not caused by cochlear suppression, as evidenced from the constant excitatory input activity during acoustic stimulation in the inhibitory sideband.

Most in vivo studies that reported a contribution of both glycine and GABA to acoustic signal processing in the $\mathrm{CN}$ could not specifically assign particular role to either transmitter (Caspary et al., 1994; Backoff et al., 1997; Dehmel et al., 2010). It remains an intriguing question whether the respective transmitters may be differentially associated with specific auditory mechanisms, as suggested previously (Ebert and Ostwald, 1995; Gai and Carney, 2008). Our results argue that the potent glycinergic inhibition on SBCs primarily determines the slow filtering properties. However, this study also reveals the particular role of $\mathrm{GABA}_{\mathrm{A}}$ receptors on SBCs. By mediating dynamic enhancement of inhibitory strength and shaping its duration, postsynaptic GABAergic transmission can contribute to an effective gain control.

\section{References}

Apostolides PF, Trussell LO (2013) Rapid, activity-independent turnover of vesicular transmitter content at a mixed glycine/GABA synapse. J Neurosci 33:4768-4781. CrossRef Medline

Arnott RH, Wallace MN, Shackleton TM, Palmer AR (2004) Onset neurones in the anteroventral cochlear nucleus project to the dorsal cochlear nucleus. J Assoc Res Otolaryngol 5:153-170. CrossRef Medline

Awatramani GB, Turecek R, Trussell LO (2004) Inhibitory control at a synaptic relay. J Neurosci 24:2643-2647. CrossRef Medline

Awatramani GB, Turecek R, Trussell LO (2005) Staggered development of GABAergic and glycinergic transmission in the MNTB. J Neurophysiol 93:819-828. CrossRef Medline

Backoff PM, Palombi PS, Caspary DM (1997) Glycinergic and GABAergic inputs affect short-term suppression in the cochlear nucleus. Hear Res 110:155-163. CrossRef Medline

Balakrishnan V, Trussell LO (2008) Synaptic inputs to granule cells of the dorsal cochlear nucleus. J Neurophysiol 99:208-219. CrossRef Medline

Balakrishnan V, Kuo SP, Roberts PD, Trussell LO (2009) Slow glycinergic transmission mediated by transmitter pooling. Nat Neurosci 12:286-294. CrossRef Medline

Bazwinsky I, Härtig W, Rübsamen R (2008) Characterization of cochlear nucleus principal cells of Meriones unguiculatus and Monodelphis domestica by use of calcium-binding protein immunolabeling. J Chem Neuroanat 35:158-174. CrossRef Medline

Beato M, Burzomato V, Sivilotti LG (2007) The kinetics of inhibition of rat recombinant heteromeric alphalbeta glycine receptors by the low-affinity antagonist SR-95531. J Physiol 580:171-179. CrossRef Medline

Bellingham MC, Walmsley B (1999) A novel presynaptic inhibitory mechanism underlies paired pulse depression at a fast central synapse. Neuron 23:159-170. CrossRef Medline

Benson CG, Potashner SJ (1990) Retrograde transport of [ $\left.{ }^{3} \mathrm{H}\right]$ glycine from the cochlear nucleus to the superior olive in the guinea pig. J Comp Neurol 296:415-426. CrossRef Medline

Blackburn CC, Sachs MB (1989) Classification of unit types in the anteroventral cochlear nucleus: PST histograms and regularity analysis. J Neurophysiol 62:1303-1329. Medline

Bohlhalter S, Mohler H, Fritschy JM (1994) Inhibitory neurotransmission in rat spinal cord: co-localization of glycine- and GABAA-receptors at GABAergic synaptic contacts demonstrated by triple immunofluorescence staining. Brain Res 642:59-69. CrossRef Medline

Borst JG (2010) The low synaptic release probability in vivo. Trends Neurosci 33:259-266. CrossRef Medline

Burger PM, Hell J, Mehl E, Krasel C, Lottspeich F, Jahn R (1991) GABA and glycine in synaptic vesicles: storage and transport characteristics. Neuron 7:287-293. CrossRef Medline

Campagnola L, Manis PB (2014) A map of functional synaptic connectivity in the mouse anteroventral cochlear nucleus. J Neurosci 34:2214-2230. CrossRef Medline

Campos ML, de Cabo C, Wisden W, Juiz JM, Merlo D (2001) Expression of GABA(A) receptor subunits in rat brainstem auditory pathways: cochlear nuclei, superior olivary complex and nucleus of the lateral lemniscus. Neuroscience 102:625-638. CrossRef Medline

Cao XJ, Shatadal S, Oertel D (2007) Voltage-sensitive conductances of bushy cells of the Mammalian ventral cochlear nucleus. J Neurophysiol 97:3961-3975. CrossRef Medline

Caspary DM, Backoff PM, Finlayson PG, Palombi PS (1994) Inhibitory inputs modulate discharge rate within frequency receptive fields of anteroventral cochlear nucleus neurons. J Neurophysiol 72:2124-2133. Medline

Caspary DM, Ling L, Turner JG, Hughes LF (2008) Inhibitory neurotransmission, plasticity and aging in the mammalian central auditory system. J Exp Biol 211:1781-1791. CrossRef Medline

Chanda S, Xu-Friedman MA (2010) Neuromodulation by GABA converts a relay into a coincidence detector. J Neurophysiol 104:2063-2074. CrossRef Medline

Chirila FV, Rowland KC, Thompson JM, Spirou GA (2007) Development of gerbil medial superior olive: integration of temporally delayed excitation and inhibition at physiological temperature. J Physiol 584:167-190. CrossRef Medline

Couchman K, Grothe B, Felmy F (2010) Medial superior olivary neurons receive surprisingly few excitatory and inhibitory inputs with balanced strength and short-term dynamics. J Neurosci 30:17111-17121. CrossRef Medline 
Crins TT, Rusu SI, Rodríguez-Contreras A, Borst JG (2011) Developmental changes in short-term plasticity at the rat calyx of held synapse. J Neurosci 31:11706-11717. CrossRef Medline

Dehmel S, Kopp-Scheinpflug C, Weick M, Dörrscheidt GJ, Rübsamen R (2010) Transmission of phase-coupling accuracy from the auditory nerve to spherical bushy cells in the Mongolian gerbil. Hear Res 268:234249. CrossRef Medline

Dietz B, Jovanovic S, Wielsch B, Nerlich J, Rübsamen R, Milenkovic I (2012) Purinergic modulation of neuronal activity in developing auditory brainstem. J Neurosci 32:10699-10712. CrossRef Medline

Dumba JS, Irish PS, Anderson NL, Westrum LE (1998) Electron microscopic analysis of gamma-aminobutyric acid and glycine colocalization in rat trigeminal subnucleus caudalis. Brain Res 806:16-25. CrossRef Medline

Ebert U, Ostwald J (1995) GABA can improve acoustic contrast in the rat ventral cochlear nucleus. Exp Brain Res 104:310-322. Medline

Englitz B, Tolnai S, Typlt M, Jost J, Rübsamen R (2009) Reliability of synaptic transmission at the synapses of Held in vivo under acoustic stimulation. PLoS One 4:e7014. CrossRef Medline

Fischl MJ, Combs TD, Klug A, Grothe B, Burger RM (2012) Modulation of synaptic input by GABAB receptors improves coincidence detection for computation of sound location. J Physiol 590:3047-3066. CrossRef Medline

Friauf E, Rust MB, Schulenborg T, Hirtz JJ (2011) Chloride cotransporters, chloride homeostasis, and synaptic inhibition in the developing auditory system. Hear Res 279:96-110. CrossRef Medline

Fritschy JM, Paysan J, Enna A, Mohler H (1994) Switch in the expression of rat GABAA-receptor subtypes during postnatal development: an immunohistochemical study. J Neurosci 14:5302-5324. Medline

Gai Y, Carney LH (2008) Influence of inhibitory inputs on rate and timing of responses in the anteroventral cochlear nucleus. J Neurophysiol 99: 1077-1095. CrossRef Medline

Goodman D, Brette R (2008) Brian: a simulator for spiking neural networks in python. Front Neuroinform 2:5. CrossRef Medline

Grothe B (2000) The evolution of temporal processing in the medial superior olive, an auditory brainstem structure. Prog Neurobiol 61:581-610. CrossRef Medline

Hackney CCM, Osen KKK, Kolston J (1990) Anatomy of the cochlear nuclear complex of guinea pig. Anat Embryol 182:123-149. Medline

Harty TP, Manis PB (1996) Glycine-evoked currents in acutely dissociated neurons of the guinea pig ventral cochlear nucleus. J Neurophysiol 75: 2300-2311. Medline

Hines ML, Carnevale NT (1997) The NEURON simulation environment. Neural Comput 9:1179-1209. CrossRef Medline

Huang ZJ, Di Cristo G, Ango F (2007) Development of GABA innervation in the cerebral and cerebellar cortices. Nat Rev Neurosci 8:673-686. CrossRef Medline

Jonas P, Bischofberger J, Sandkühler J (1998) Corelease of two fast neurotransmitters at a central synapse. Science 281:419-424. CrossRef Medline

Joris PX, Smith PH (2008) The volley theory and the spherical cell puzzle. Neuroscience 154:65-76. CrossRef Medline

Joris PX, Carney LH, Smith PH, Yin TC (1994) Enhancement of neural synchronization in the anteroventral cochlear nucleus: I. Responses to tones at the characteristic frequency. J Neurophysiol 71:1022-1036. Medline

Juiz JM, Helfert RH, Bonneau JM, Campos ML, Altschuler RA (1996) Distribution of glycine and GABA immunoreactivities in the cochlear nucleus: quantitative patterns of putative inhibitory inputs on three cell types. J Hirnforsch 37:561-574. Medline

Kakazu Y, Akaike N, Komiyama S, Nabekura J (1999) Regulation of intracellular chloride by cotransporters in developing lateral superior olive neurons. J Neurosci 19:2843-2851. Medline

Kim G, Kandler K (2010) Synaptic changes underlying the strengthening of $\mathrm{GABA} /$ glycinergic connections in the developing lateral superior olive. Neuroscience 171:924-933. CrossRef Medline

Kolston J, Osen KK, Hackney CM, Ottersen OP, Storm-Mathisen J (1992) An atlas of glycine- and GABA-like immunoreactivity and colocalization in the cochlear nuclear complex of the guinea pig. Anat Embryol (Berl) 186:443-465. Medline

Kopp-Scheinpflug C, Dehmel S, Dörrscheidt GJ, Rübsamen R (2002) Interaction of excitation and inhibition in anteroventral cochlear nucleus neurons that receive large endbulb synaptic endings. J Neurosci 22: 11004-11018. Medline

Kotak VC, Korada S, Schwartz IR, Sanes DH (1998) A developmental shift from GABAergic to glycinergic transmission in the central auditory system. J Neurosci 18:4646-4655. Medline

Kramer F, Griesemer D, Bakker D, Brill S, Franke J, Frotscher E, Friauf E (2014) Inhibitory glycinergic neurotransmission in the mammalian auditory brainstem upon prolonged stimulation: short-term plasticity and synaptic reliability. Front Neural Circuits 8:14. CrossRef Medline

Kuenzel T, Borst JG, van der Heijden M (2011) Factors controlling the input-output relationship of spherical bushy cells in the gerbil cochlear nucleus. J Neurosci 31:4260-4273. CrossRef Medline

Kuhlmann L, Burkitt AN, Paolini A, Clark GM (2002) Summation of spatiotemporal input patterns in leaky integrate-and-fire neurons: application to neurons in the cochlear nucleus receiving converging auditory nerve fiber input. J Comput Neurosci 12:55-73. CrossRef Medline

Kullmann PH, Kandler K (2001) Glycinergic/GABAergic synapses in the lateral superior olive are excitatory in neonatal C57BL/6J mice. Brain Res Dev Brain Res 131:143-147. CrossRef Medline

Kullmann PH, Ene FA, Kandler K (2002) Glycinergic and GABAergic calcium responses in the developing lateral superior olive. Eur J Neurosci 15:1093-1104. CrossRef Medline

Kurt S, Crook JM, Ohl FW, Scheich H, Schulze H (2006) Differential effects of iontophoretic in vivo application of the GABA(A)-antagonists bicuculline and gabazine in sensory cortex. Hear Res 212:224-235. CrossRef Medline

Legendre P (2001) The glycinergic inhibitory synapse. Cell Mol Life Sci 58: 760-793. CrossRef Medline

Lehmann K, Steinecke A, Bolz J (2012) GABA through the ages: regulation of cortical function and plasticity by inhibitory interneurons. Neural Plast 2012:892784. CrossRef Medline

Levene H (1960) Robust tests for equality of variances. In: Contributions to probability and statistic, pp 278-292. Stanford, CA: Stanford University.

Lim R, Alvarez FJ, Walmsley B (1999) Quantal size is correlated with receptor cluster area at glycinergic synapses in the rat brainstem. J Physiol 516:505-512. CrossRef Medline

Lim R, Alvarez FJ, Walmsley B (2000) GABA mediates presynaptic inhibition at glycinergic synapses in a rat auditory brainstem nucleus. J Physiol 525:447-459. CrossRef Medline

Lu T, Trussell LO (2000) Inhibitory transmission mediated by asynchronous transmitter release. Neuron 26:683-694. CrossRef Medline

Luján R, de Cabo C, Juiz JM (2008) Inhibitory synaptogenesis in the rat anteroventral cochlear nucleus. Neuroscience 154:315-328. CrossRef Medline

Magnusson AK, Kapfer C, Grothe B, Koch U (2005) Maturation of glycinergic inhibition in the gerbil medial superior olive after hearing onset. J Physiol 568:497-512. CrossRef Medline

Mahendrasingam S, Wallam CA, Hackney CM (2000) An immunogold investigation of the relationship between the amino acids GABA and glycine and their transporters in terminals in the guinea-pig anteroventral cochlear nucleus. Brain Res 887:477-481. CrossRef Medline

Mahendrasingam S, Wallam CA, Polwart A, Hackney CM (2004) An immunogold investigation of the distribution of GABA and glycine in nerve terminals on the somata of spherical bushy cells in the anteroventral cochlear nucleus of guinea pig. Eur J Neurosci 19:993-1004. CrossRef Medline

McGinley MJ, Oertel D (2006) Rate thresholds determine the precision of temporal integration in principal cells of the ventral cochlear nucleus. Hear Res 216:52-63. CrossRef Medline

Milenkovic I, Rübsamen R (2011) Development of the chloride homeostasis in the auditory brainstem. Physiol Res 60 [Suppl 1]:S15-S27.

Milenkovic I, Witte M, Turecek R, Heinrich M, Reinert T, Rübsamen R (2007) Development of chloride-mediated inhibition in neurons of the anteroventral cochlear nucleus of gerbil (Meriones unguiculatus). J Neurophysiol 98:1634-1644. CrossRef Medline

Milenkovic I, Rinke I, Witte M, Dietz B, Rübsamen R (2009) P2 receptormediated signaling in spherical bushy cells of the mammalian cochlear nucleus. J Neurophysiol 102:1821-1833. CrossRef Medline

Nabekura J, Katsurabayashi S, Kakazu Y, Shibata S, Matsubara A, Jinno S, Mizoguchi Y, Sasaki A, Ishibashi H (2004) Developmental switch from GABA to glycine release in single central synaptic terminals. Nat Neurosci 7:17-23. CrossRef Medline 
Oertel D, Wickesberg RE (1993) Glycinergic inhibition in the cochlear nuclei: evidence for tuberculoventral neurons being glycinergic. In: NATO Research Workshop on the Mammalian Cochlear Nuclei: Organization and Function (Merchan MA, Juiz JM, Godfrey DA, Mugnaini E, eds), pp 225-237. Salamanca, Spain: Plenum.

Ostapoff EM, Feng JJ, Morest DK (1994) A physiological and structural study of neuron types in the cochlear nucleus. II. Neuron types and their structural correlation with response properties. J Comp Neurol 346:1942. Medline

Ostapoff EM, Benson CG, Saint Marie RL (1997) GABA- and glycineimmunoreactive projections from the superior olivary complex to the cochlear nucleus in guinea pig. J Comp Neurol 381:500-512. CrossRef Medline

Paolini AG, FitzGerald JV, Burkitt AN, Clark GM (2001) Temporal processing from the auditory nerve to the medial nucleus of the trapezoid body in the rat. Hear Res 159:101-116. CrossRef Medline

Pfeiffer RR (1966) Anteroventral cochlear nucleus: wave forms of extracellularly recorded spike potentials. Science 154:667-668. CrossRef Medline

Pliss L, Yang H, Xu-Friedman MA (2009) Context-dependent effects of NMDA receptors on precise timing information at the endbulb of held in the cochlear nucleus. J Neurophysiol 102:2627-2637. CrossRef Medline

Price GD, Trussell LO (2006) Estimate of the chloride concentration in a central glutamatergic terminal: a gramicidin perforated-patch study on the calyx of Held. J Neurosci 26:11432-11436. CrossRef Medline

Prieto JJ, Peterson BA, Winer JA (1994) Morphology and spatial distribution of GABAergic neurons in cat primary auditory cortex (AI). J Comp Neurol 344:349-382. CrossRef Medline

Rothman JS, Manis PB (2003) The roles potassium currents play in regulating the electrical activity of ventral cochlear nucleus neurons. J Neurophysiol 89:3097-3113. CrossRef Medline

Rothman JS, Young ED, Manis PB (1993) Convergence of auditory nerve fibers onto bushy cells in the ventral cochlear nucleus: implications of a computational model. J Neurophysiol 70:2562-2583. Medline

Rouiller EM, Ryugo DK (1984) Intracellular marking of physiologically characterized cells in the ventral cochlear nucleus of the cat. J Comp Neurol 225:167-186. Medline

Russier M, Kopysova IL, Ankri N, Ferrand N, Debanne D (2002) GABA and glycine co-release optimizes functional inhibition in rat brainstem motoneurons in vitro. J Physiol 541:123-137. CrossRef Medline

Saint Marie RL, Benson CG, Ostapoff EM, Morest DK (1991) Glycine immunoreactive projections from the dorsal to the anteroventral cochlear nucleus. Hear Res 51:11-28. CrossRef Medline

Sanes DH, Friauf E (2000) Development and influence of inhibition in the lateral superior olivary nucleus. Hear Res 147:46-58. CrossRef Medline

Sanes DH, Kotak VC (2011) Developmental plasticity of auditory cortical inhibitory synapses. Hear Res 279:140-148. CrossRef Medline

Smith PH, Rhode WS (1989) Structural and functional properties distinguish two types of multipolar cells in the ventral cochlear nucleus. J Comp Neurol 282:595-616. CrossRef Medline

Smith PH, Joris PX, Yin TC (1993) Projections of physiologically characterized spherical bushy cell axons from the cochlear nucleus of the cat: evidence for delay lines to the medial superior olive. J Comp Neurol 331: 245-260. CrossRef Medline

Shapiro S, Wilk M (1965) An analysis of variance test for normality. Biometrika 52:591-611.

Shapiro SS, Francia RS (1972) An approximate analysis of variance test for normality. J Am Stat Assoc 67:215-216.

Stange A, Myoga MH, Lingner A, Ford MC, Alexandrova O, Felmy F, Pecka M, Siveke I, Grothe B (2013) Adaptation in sound localization: from
GABA(B) receptor-mediated synaptic modulation to perception. Nat Neurosci 16:1840-1847. CrossRef Medline

Todd AJ, Watt C, Spike RC, Sieghart W (1996) Colocalization of GABA, glycine, and their receptors at synapses in the rat spinal cord. J Neurosci 16:974-982. Medline

Tolbert LP, Morest DK, Yurgelun-Todd DA (1982) The neuronal architecture of the anteroventral cochlear nucleus of the cat in the region of the cochlear nerve root: electron microscopy. Neuroscience 7:3013-3030. Medline

Triller A, Cluzeaud F, Korn H (1987) $\gamma$-Aminobutyric acid-containing terminals can be apposed to glycine receptors at central synapses. J Cell Biol 104:947-956. CrossRef Medline

Typlt M, Haustein MD, Dietz B, Steinert JR, Witte M, Englitz B, Milenkovic I, Kopp-Scheinpflug C, Forsythe ID, Rübsamen R (2010) Presynaptic and postsynaptic origin of multicomponent extracellular waveforms at the endbulb of Held-spherical bushy cell synapse. Eur J Neurosci 31:15741581. CrossRef Medline

Typlt M, Englitz B, Sonntag M, Dehmel S, Kopp-Scheinpflug C, Ruebsamen R (2012) Multidimensional characterization and differentiation of neurons in the anteroventral cochlear nucleus. PLoS One 7:e29965. CrossRef Medline

Varela JA, Sen K, Gibson J, Fost J, Abbott LF, Nelson SB (1997) A quantitative description of short-term plasticity at excitatory synapses in layer $2 / 3$ of rat primary visual cortex. J Neurosci 17:7926-7940. Medline

Wang Y, Manis PB (2008) Short-term synaptic depression and recovery at the mature mammalian endbulb of Held synapse in mice. J Neurophysiol 100:1255-1264. CrossRef Medline

Wang Y, Ren C, Manis PB (2010) Endbulb synaptic depression within the range of presynaptic spontaneous firing and its impact on the firing reliability of cochlear nucleus bushy neurons. Hear Res 270:101-119. CrossRef Medline

Wenthold RJ (1991) Neurotransmitters of brainstem auditory nuclei. In: Neurobiology of hearing: the central auditory system (Altschuler RA, Bobbin RP, Clopton BM, Hoffman DW, eds), pp 121-139. New York: Raven.

Wenthold RJ, Parakkal MH, Oberdorfer MD, Altschuler RA (1988) Glycine receptor immunoreactivity in the ventral cochlear nucleus of the guinea pig. J Comp Neurol 276:423-435. CrossRef Medline

Wickesberg RE, Oertel D (1990) Delayed, frequency-specific inhibition in the cochlear nuclei of mice: a mechanism for monaural echo suppression. J Neurosci 10:1762-1768. Medline

Winter IM, Palmer AR (1990) Responses of single units in the anteroventral cochlear nucleus of the guinea pig. Hear Res 44:161-178. CrossRef Medline

Witte M, Reinert T, Dietz B, Nerlich J, Rübsamen R, Milenkovic I (2014) Depolarizing chloride gradient in developing cochlear nucleus neurons: underlying mechanism and implication for calcium signaling. Neuroscience 261:207-222. CrossRef Medline

Xie R, Manis PB (2013) Target-specific IPSC kinetics promote temporal processing in auditory parallel pathways. J Neurosci 33:1598-1614. CrossRef Medline

Xu-Friedman MA, Regehr WG (2005) Dynamic-clamp analysis of the effects of convergence on spike timing: II. Few synaptic inputs. J Neurophysiol 94:2526-2534. CrossRef Medline

Yang H, Xu-Friedman MA (2008) Relative roles of different mechanisms of depression at the mouse endbulb of Held. J Neurophysiol 99:2510-2521. CrossRef Medline

Yang H, Xu-Friedman MA (2009) Impact of synaptic depression on spike timing at the endbulb of Held. J Neurophysiol 102:1699-1710. CrossRef Medline 